\title{
Public procurement in Big Science: politics or technology? The case of CERN
}

\author{
Andrea Bastianin \\ Department of Economics, Management, \\ and Quantitative Methods (DEMM) \\ University of Milan
}

\author{
Chiara F. Del Bo \\ Department of Economics, Management, \\ and Quantitative Methods (DEMM) \\ University of Milan
}

November 21, 2020

\begin{abstract}
Public procurement from Big Science Centers (BSCs) yields a variety of spillover effects that can ultimately have growth enhancing consequences for their Member States (MS). We study the determinants of procurement for the biggest research infrastructure ever built: the Large Hadron Collider (LHC) at CERN. A unique database of firms that have registered to become industrial partners of the LHC program allows us to estimate the determinants for potential suppliers of receiving an order from CERN. We compare the relative weight of firms' technological features and CERN's procurement rules aimed at securing a juste retour for its MS. While, in accordance to CERN's procurement rules our results highlight the role of both technological factors and political constraints, we also show the existence of a premium toward Swiss and French firms. We document that the constraints related with the achievement of a juste retour affect - directly or indirectly the procurement policy of many European BSCs and international bodies whose budget is financed by the public funds of their MS. Therefore, our results have policy implications that go beyond our empirical application.
\end{abstract}

Key Words: big science, CERN, juste retour, public procurement.

JEL Codes: C21; C25; H57; O32; O38. ods (DEMM), University of Milano, Via Conservatorio, 7, 20122, Milan - Italy. 
Email: andrea.bastianin@unimi.it. 


\section{Introduction}

Public procurement is increasingly used as strategic lever by governments; in fact, large purchases of goods and services can also be exploited to pursue broader targets related to economic and innovation policies. As of 2016, 24 OECD countries used public procurement as a demand-side innovation policy (OECD, 2016; Edler and Georghiou, 2007). The importance of procurement as a policy tool is explained, inter alia, by its volume. For European OECD countries government procurement expenditure in 2015 accounted on average for $11.9 \%$ of Gross Domestic Product (GDP), ranging from 7.3\% of GDP for Ireland to $20.2 \%$ of GDP for the Netherlands (OECD, 2016).

By virtue of the sheer size of their research infrastructures, scientific instruments and the generous budget they manage, public procurement from Big Science Centers (BSCs) can be an important tool for the innovation policies of governments funding them. While BSCs are purposefully built to address broad and complex research questions, their Member States (MS) fund them not only for the promise of scientific discoveries, but also for the the economic and societal spillovers they can generate (Autio et al., 2004; Florio et al., 2018a; Helmers and Overman, 2017; Vuola and Hameri, 2006). For this reason, the procurement rules of several European BSCs incorporate, or are inspired by, the so-called juste retour concept. This is a general principle implying that MS should be compensated for their contribution to the BSC's budget by means of an equitable distribution of procurement contracts. Singling out which factors increase the likelihood of becoming a supplier of BSCs is of interest for those designing their procurement rules. Moreover, identifying such factors is key for firms wishing to gain a better understanding of the paths and potential bottlenecks they might face when participating to tenders.

The present paper focuses on the tension between firms' embodied technological knowledge and BSCs' procedures and political constraints. Our study relies on a unique crosssection database of firms that have registered to become industrial partners for the construction of the biggest research infrastructure ever built: the Large Hadron Collider (LHC) at the European Organization for Nuclear Research (CERN). We compare the relative weight of firms' technological features and CERN's procurement rules aimed at securing a juste 
retour for its MS. In accordance to CERN's procurement rules our results highlight that the probability of becoming suppliers of the LHC project is positively associated with technological factors as well as with political constraints. We also document the that the likelihood of becoming suppliers increases for Swiss and French firms.

We contribute to different strands of the literature. First, the branch of the literature that deals with the relationship between BSCs and their industrial partners has shown that there are a variety of benefits for all parties involved (Bressan and Bianchi-Streit, 2005; Helmers and Overman, 2017; Vuola and Hameri, 2006), but has remained silent about the determinants of the procurement process. ${ }^{1}$

Second, our results can be linked to the literature on the organizational aspects of public procurement (Christensen et al., 2020; Patrucco et al., 2019). While these contributions do not consider explicitly the special case of intergovernmental institutions - such as CERN - but focus on how procurement by public bodies in general is organized, they provide an interpretative lens that is related to our results. These works suggest that the design of the procurement rules, both within and outside the public organization, have an impact on the outcomes and performance of the process. This implies that the internal procedures governing the allocation of contracts within CERN is expected to be correlated with the outcome of the industrial partner selection process, as our empirical analyses indeed suggest.

Our results highlighting the existence of a home premium in obtaining CERN contracts for firms located in Switzerland and France can also be linked to the literature explaining the relation between the geographic location of bidders and the allocation of public procurement contracts. Rickard and Kono (2014) for example, and, more recently, Carboni et al. (2018), document that governments often discriminate in favor of domestic bidders when purchasing goods and services through public procurement, thus giving rise to a home premium effect.

The rest of the paper is organized as follows. Section 2 provides a background on CERN, its procurement policy and discusses the juste retour principle in BSCs. Data, methods and research questions are presented in Section 3. Section 4 is devoted to descriptive statistics

\footnotetext{
${ }^{1}$ These benefits include technological innovation, learning and other spillover effects (Florio et al., 2018b; Tuertscher et al., 2014) that also generate increased sales and cost savings for hi-tech firms (Bianchi-Streit et al., 1984; Castelnovo et al., 2018).
} 
and main results, while additional empirical evidence and robustness checks appear in Section 5. Section 6 discusses and concludes.

\section{Procurement policy and the juste retour principle in Big Science}

\subsection{CERN: organization and scientific mission}

CERN, located in Geneva, Switzerland, is a leading research institution in the field of fundamental physics whose mission is to push the frontiers of science and technology (Nilsen and Anelli, 2016). There are $23 \mathrm{MS}$ - each with a single vote at the CERN Council - that run the Organization, contribute to capital and operating costs of its programs and express their vote in the Council that approves the Organization's activities, adopts its budget and reviews expenditure. ${ }^{2}$ CERN research involves over 17,500 people belonging to about 1,500 institutes from all over the world (CERN, 2018).

The LHC, built between 1995 and 2008, is hosted in a 27km circumference underground tunnel located beneath the border between Switzerland and France. Although the LHC is installed in the tunnel that hosted CERN's previous big accelerator - the Large ElectronPositron Collider, dismantled in 2000 - its construction involved additional civil engineering works (e.g. for the excavation of large caverns that host the detectors) ${ }^{3}$. The main scientific goal of the LHC is to test the limits of the Standard Model of particle physics, that is a set of theories embodying the current understanding of fundamental forces and particles in the Universe, as well as their interactions (Evans, 2016).

As shown in Figure 1, the LHC is part of an accelerator complex, namely a succession of machines with increasingly higher energies (Evans, 2016). Each machine accelerates a beam

\footnotetext{
${ }^{2}$ As of July 2020 MS are: Austria, Belgium, Bulgaria, Czech Republic, Denmark, Finland, France, Germany, Greece, Hungary, Israel, Italy, Netherlands, Norway, Poland, Portugal, Romania, Serbia, Slovakia, Spain, Sweden, Switzerland and United Kingdom. Cyprus and Slovenia are Associate MS in the pre-stage to Membership. Croatia, India, Lithuania, Pakistan, Turkey and Ukraine are Associate MS.

${ }^{3}$ Detectors are machines that gather information used by physicists to identify particles. The largest detector at the LHC is ATLAS. It weighs 7,000 tonnes and has the dimensions of a cylinder - 46 meters long and 25 meters in diameter - that sits in a cavern 100 meters below ground (https://atlas.cern).
} 
Figure 1: The accelerator complex at CERN

\section{CERN's accelerator complex}

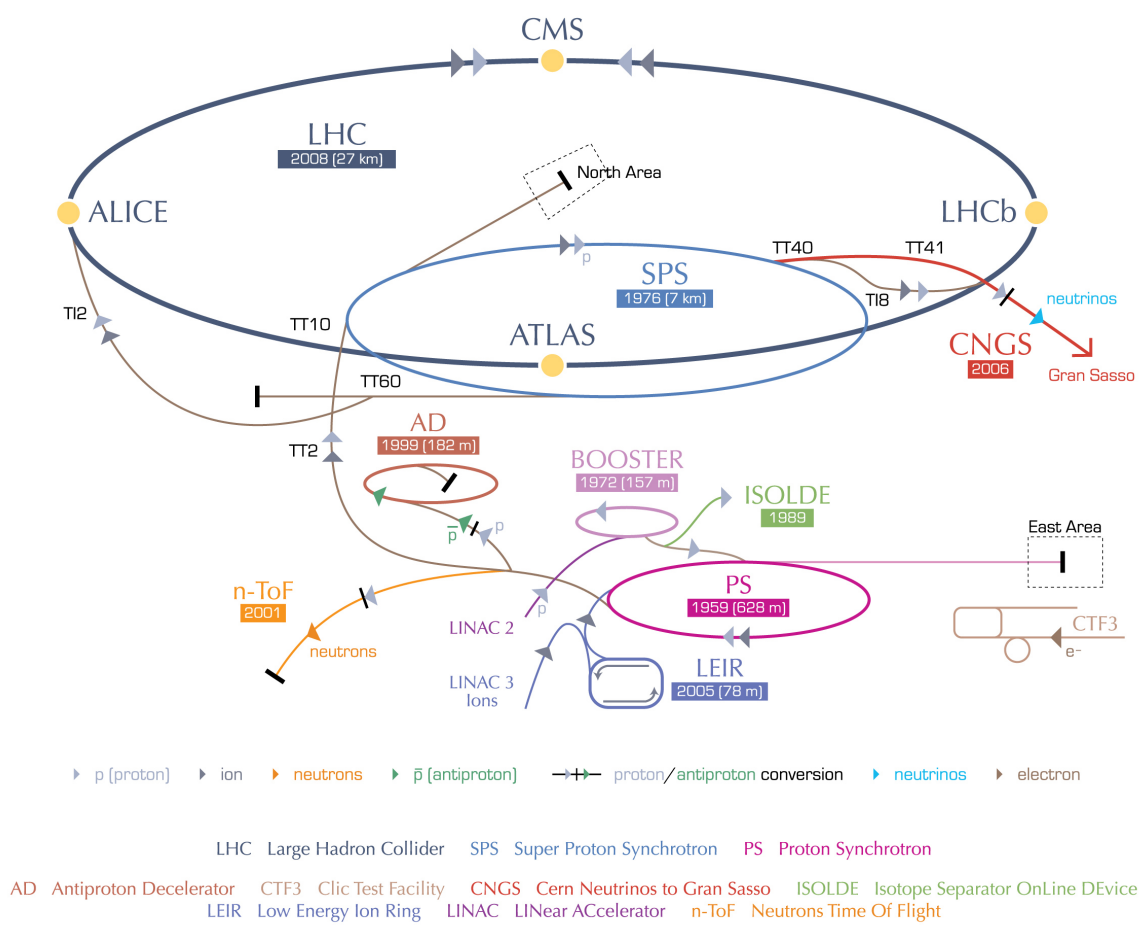

of particles before injecting it into the next one in the chain. Inside the LHC, which is the last element of this chain, two beams of particles travelling in opposite directions, at close to the speed of light, are made to collide at four points around the machine. There are seven experiments - run by collaborations of scientists from institutes from all over the world installed at the LHC (i.e. ALICE, ATLAS, CMS, LHCb, LHCfm, TOTEM, MoEDAL) each with a different research goal. The four biggest experiments are ALICE, ATLAS, CMS and $\mathrm{LHCb}$; these are installed in underground caverns built around the four collision points of the LHC beams. CERN is a member and finances of each of these experimental collaborations, but these are individual entities funded independently from CERN.

The total construction cost of LHC was of 4,332 MCHF (CERN, 2019b). During the 1995-2015 period, about 4,200 firms were involved in CERN's activities (CERN, 2019a). New solutions developed for research purposes by CERN with the involvement of the in- 
dustry have found applications in many fields including computing, medical, biomedical and aerospatial technologies (Battistoni et al., 2016; Florio et al., 2018a; Jewell, 2008), suggesting the importance for society as a whole of its activities, due to the spillovers in several fields and across different actors.

While research at CERN currently focuses on LHC operations, there are also experiments at other accelerators and facilities (see Figure 1). CERN's Medium-Term Plan helps obtaining a rough estimate of the relative importance of LHC and non-LHC experiments. The total expenses over the 2017-22 period are expected to amount to 7,145 MCHF (CERN, 2017, p. 16). A considerable amount of this budget, 4,615 MCHF (64.6\%), is devoted to scientific programs, projects and studies, while the rest is made up of centralized expenses (including personnel and energy) and other outlays for infrastructures and services. Expenses for the LHC program represent $60.6 \%$ of this amount (or $39.1 \%$ of the total budget), while the remaining $39.4 \%$ (or $25.5 \%$ of the total budget) is devoted to non-LHC activities.

\subsection{Procurement policy in European Big Science Centres}

The juste retour principle inspires - with different nuances - not just the procurement policy of CERN, but also that of many other European BSCs and international bodies, where many sovereign countries contribute with their public funds to the institution's budget. The idea of a juste retour finds its roots in the 1984 Fontainebleau Agreement when, during the European Council, the UK Prime Minister Margaret Thatcher negotiated a reduction in the British contribution to the EU budget (Le Cacheux, 2005). This reduction was seen as a "compensation" for any shortfall between what the UK paid into the EU and what it got back. In particular, it was asked on the premise that, because of its relatively small farming industry, the UK benefited less than other countries from the Common Agricultural Policy.

Support for this principle is not universal and it has sparked several criticisms at the European level. These include a warning that the principle might go against the principles of the EU (Physics World, 1988) and that there might be a conflict with the requirement of granting the contract to the lowest bidder (OECD, 2010). Nevertheless, constraints related with the achievement of a juste retour condition the procurement policy of many BSCs in 
Europe. Its rationale, in the context of intergovernmental research centers, is to ensure that the MS receive a value of contracts, via procurement, which is proportional to their contribution to the aggregate budget. Before discussing CERN's procurement policy in detail, it is instructive to provide an overview of the practices in other European BSCs and see if and how the juste retour principle is implemented. We thus focus on four leading BSCs with distinct scientific missions. Although procurement procedures at CERN and in these BSCs have some features in common (e.g. competitive tenders are used to allocate orders above a certain threshold in most of these BSCs and the relevance of technological competencies of firms in determining the outcome of the procurement process) not all of them implement the juste retour principle. ${ }^{4}$

European Spatial Agency (ESA). ESA, since its establishment in 1975, aims at developing the European space industry and enhancing its competitiveness on the international markets, and is an intergovernmental organization with 22 MS. A key principle governing the procurement process is related to the concept of geographical distribution or fair return (https://www.esa.int/About_Us). This has led, since 1997, to the application of a strict juste retour principle (Physics World, 1988): the industrial return coefficient (i.e. the ratio between the country's share in the weighted value of contracts, and its share in the contributions to ESA's budget), should amount to $98 \%$, in a specified time frame (http://www.esa.int/esapub). An Industrial Policy Committee is in charge of defining, implementing and monitoring the Agency's Industrial Policy and ensures fairness in access to procurement to all firms, with special attention to small and medium enterprises (https://www.esa.int/About_Us/Law_at_ESA). Invitations to tender are advertised on an online repository and are awarded through open or restricted competition and direct negotiation. The geographical return principle informs all procurement activity. As an indication of the order of magnitude of ESA's procurement activities, current forecasts suggest that the budget for ongoing and planned programs between 2020 and 2024 is of 28,500 M EUR

\footnotetext{
${ }^{4}$ We exclude other prominent non-European BSCs such the National Aeronautics and Space Administration (NASA) because it is an independent agency of the Federal Government of the US and, as such, is not an intergovernmental organization with different MS. However, since NASA is financed by the federal budget, which in turn is financed by the different States through their fiscal revenues, there are potential similarities (not developed in the present paper) with the multi-country nature of the organizations examined in the present paper.
} 
(https://www.bsbf2020.org).

European Synchrotron Radiation Facility (ESFR). The ESRF - a research facility located in Grenoble, France financed and supported by 13 MS and 9 associate countries - is the most intense source of synchrotron-generated light that acts as a sort of "super-microscope" recording the position and motion of atoms in condensed and living matter. Researchers at ESRF explore materials and living matter in many fields including chemistry, material physics, archaeology, biology, medical applications and nanotechnologies. Purchases of value above 50,000 EUR are subject to calls for tender that are not publicly advertised, but are only available through the purchasing advisor authorities of different MS. Suppliers proposed by purchasing advisers are subsequently invited to tender and offers are ranked in order of preference, based on the best value for money (BVM) criteria, while also taking into account the juste retour principle. In fact, ESFR "aims for a juste retour with respect to the shareholders' contributions" (ESFRI, 2018, p. 204) and considers a return coefficient computed as the ratio of expenditures by a MS and its contribution over the past three years. Alignment rules are used to favor firms in poorly balanced MS (i.e. with a low return coefficient). In the case of a suitable offer from a firm located in a poorly balanced country that does not exceed the BVM offer by more than 10\%, the bidder is given the opportunity to align its price. If the supplier accepts to align his price to the BVM offer, the firm from the poorly balanced country becomes the first in ranking.

European Molecular Biology Laboratory (EMBL). The EMBL is an intergovernmental organization with 27 MS established in 1974 to perform fundamental research in molecular biology. It is a multi-sited research infrastructure that involves more than 1,800 people across six sites. The procurement rules of the EMBL establish that orders whose value exceeds a certain threshold must be subject to a competitive tendering process with firms located in its MS - if possible - or whose involvement can be justified on scientific grounds. Although EMBL does not have any strict obligation to provide a fair distribution of procurement orders to its MS, it does strive for delivering a juste retour to them (Cudraz, 2019).

European Spallation Source (ESS). The ESS is a multi-disciplinary research facility based on 
the world's most powerful neutron source and is under construction since 2014 in Lund, Sweden. A neutron source acts as a giant microscope and enables scientists to see and understand basic atomic structures and forces and can be used to answer important research questions in physics, chemistry, geology, biology and medicine (https://europeanspallationsource. se/). The founding members of ESS are 13 European countries. Contracts with an estimated value below 25,000 EUR are regulated by limited competition procurement and ESS assigns them to firms on a BVM basis through requests for quotation and price comparison. For contracts whose estimated value is in the 25,000 - 200,000 EUR range, ESS tries to ensure appropriate competition by inviting at least three firms from its supplier database to submit a quotation. Contracts above 200,000 EUR are advertised with a call for tenders published on the ESS website, other media and noticed to Industy Liason Officiers (ILO). In this case the ESS can opt for three different procurement procedures: open procedure, restricted procedure, competitive procedure with negotiation. The ESS does not mention anything related with the just retour principle in its procurement rules.

\subsection{Procurement policy at CERN}

CERN is an intergovernmental organization, governed by public international law and, as such potential legal disputes between CERN and its suppliers are solved via international arbitration. This also implies that CERN can establish its own procurement rules (Unnervik, 2018). These rules and procedures combine technological aspects with "political" constraints, making the process of becoming a supplier not immediately predictable. CERN's procurement policy is based on three pillars (CERN, 2015): ( $i$ ) to guarantee that contracts satisfy technical and financial requirements $(i i)$ to keep costs as low as possible and (iii) to achieve balanced industrial returns for its MS.

Several correction mechanisms are thus in place to achieve these three goals that also include compliance with the juste retour principle. However, CERN's application of such principle is more nuanced than, for example, at ESA.

The procurement process at CERN. As we can see in Figure 2, the estimated contract amount is the main parameter that defines the procurement process adopted by CERN. Orders below 
10,000 CHF are awarded to firms directly by CERN's staff without any public announcement. For orders in the range of 10,000 - 200,000 CHF, CERN's procurement service sends price inquiries - comprising technical specification, tender form, and any other relevant documents - to selected bidders. Although price enquiries are not publicly announced, when they exceed 50,000 CHF they are made available to ILOs that can suggest additional firms to CERN that retains the right to take the final decision.

For orders whose estimated amount exceeds 200,000 CHF, a public announcement of a forthcoming market survey and call for tenders is posted on CERN's Procurement website. Besides being announced online, market survey invitations are sent to firms proposed by technical/purchasing contacts, selected from CERN's database of registered companies or suggested by ILOs. Market surveys also play a signalling function informing firms about CERN future requirements and are used to update the suppliers' database.

A market survey consists of a qualification questionnaire accompanied by a brief technical description and all the necessary documentation of the order, such as technical drawings. CERN uses the qualification questionnaire to select firms to be invited for tender. Factors affecting CERN's decision include the likelihood that the selected firm will submit a bid and CERN's previous experience with the firm, if any. Moreover, the number of firms selected from each MS is affected by the MS's contribution and whether the MS is receiving a fair industrial return. 
Figure 2: The procurement process at CERN

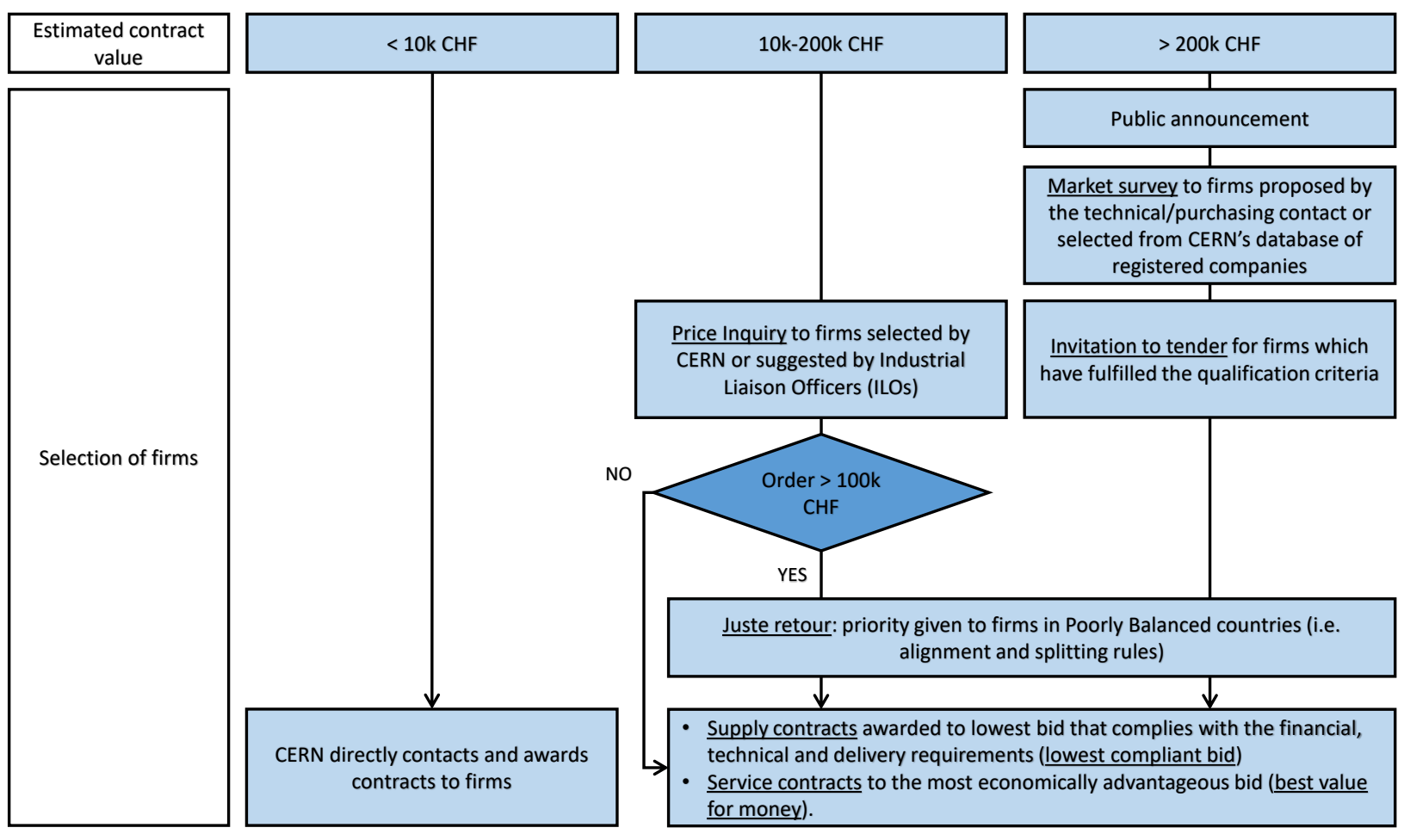

The juste retour principle at CERN. When contracts for supplies do not exceed 100,000 CHF, they are awarded to the firm submitting the lowest bid that complies with the financial, technical and delivery requirements (i.e. lowest compliant bid); similarly, service contracts below 100,000 CHF are awarded on a BVM basis. When contracts exceed 100,000 CHF they must be awarded in compliance with the achievement of "well balanced industrial return coefficients" for the MS. A MS is well balanced if its return coefficient, defined as the ratio between that country's percentage share of the value of all contracts obtained during the preceding four calendar years and its percentage contribution to the CERN Budget over the same period, is equal or greater than a certain threshold. On the contrary, poorly balanced countries have a return coefficient below this threshold.

Provided that technical, financial and delivery requirements of the contract are met, CERN has three main tools to improve the return coefficient of poorly balanced MS: limited tendering, alignment and splitting rules (see CERN, 2015, p. 37-42). In the case of limited tendering, only firms from poorly balanced MS can participate in the tendering procedures. Alignment instead gives priority to firms in poorly balanced countries, even if they are not 
providing the lowest bid. ${ }^{5}$ When technically feasible, contracts can also be split among multiple bidders to give an advantage to firms in poorly balanced countries, even if they have not posted the most economically convenient bid. See Zilverschoon (1974); Åberg and Bengtson (2015); CERN (1993a,b) for further details.

\section{Data, Methods and Research Questions}

\subsection{Data}

We have assembled a unique cross-sectional dataset, combining information sourced from CERN and from the ORBIS database maintained by Bureau van Dijk, to identify 541 firms that over the 1997-2007 period have registered with the CERN Procurement and Industrial Services Group for collaborating at the construction of the LHC. As we have seen in Section 2.1, the seven experimental collaborations installed at the LHC do have some procurement autonomy, therefore firms in our database do not include all of the entities involved in the construction of LHC.

While the construction of the LHC started in 1995 and was completed in 2008, we rely on data for 1997-2007 period because - as shown in Figure 3 - in this sub-sample we have, for each year, both LHC suppliers and potential suppliers. Potential suppliers are firms that have registered with CERN at least once but have never received an order during the time period considered in our analysis. Notice that firms have to register with the Procurement and Industrial Services Group of CERN each time they want to apply for an order. We consider potential suppliers firms that have registered at least once and actual suppliers firms that have been awarded at least one order. Although we work with a cross-section database that portrays the current classification of firms into suppliers and potential suppliers, we need to capture the time-varying nature of some variables. In these cases, variables refer to the year of first registration of firms to CERN's procurement database. Our empirical strategy exploits the fact that only 285 statistical units out of 541 - or $52.7 \%$ of the total - have

\footnotetext{
${ }^{5}$ For instance, if the lowest bid is posted by a firm in a well balanced country, CERN negotiates with the two lowest bidders in poorly balanced MS, provided that their bids fall within $20 \%$ of that of the lowest bidder. If one of these two firms aligns its price to that of the lowest bidder in the well balanced country, it gets the contract.
} 
Figure 3: Distribution of firms over registration years

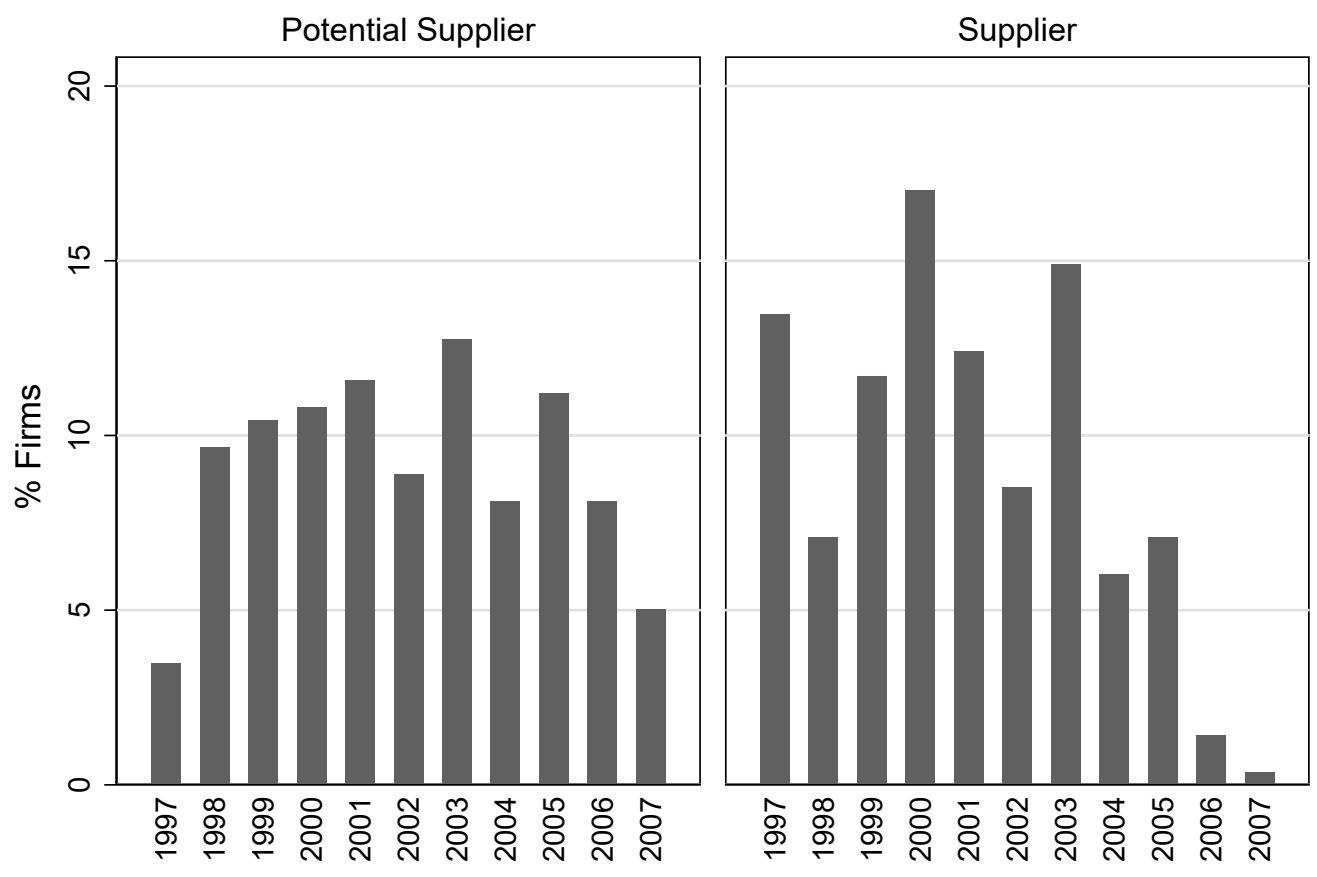

actually received at least one LHC-related order. Figure 3 shows that, while the number of LHC suppliers diminishes noticeably at the of end sample, potential suppliers are somehow more uniformly distributed, at least over the 1998-2006 period. The reduction of suppliers in 2006 and 2007 is consistent with the fact that the LHC project was completed in 2008 when the experimental activity began. Moreover, we can see that the yearly number of suppliers - and to a lower extent also that of potential suppliers - varies considerably over sample period. This variability is linked with the LHC project schedule that dictates the intensity of tendering activities for the different components of the accelerator.

\subsection{Dependent variable and empirical strategy}

We model the conditional probability of becoming an industrial partner of CERN for firms that have registered at least once to collaborate at the construction of the LHC. This is denoted as $p_{i} \equiv \operatorname{Pr}\left(y_{i}=1 \mid \mathbf{x}_{i}\right)$, where $y_{i}$ is binary variable that is equal to one for LHC suppliers and equal to zero for potential suppliers and $\mathbf{x}_{i}$ is a $(K \times 1)$ column vector collecting explanatory variables for firm $i$. Our baseline results rely on the following logit model: 


$$
y_{i}=\Lambda\left(\mathbf{x}_{i}^{\prime} \boldsymbol{\beta}\right)=\Lambda\left(\mathbf{f}_{i}^{\prime} \boldsymbol{\beta}_{\boldsymbol{f}}+\mathbf{z}_{i}^{\prime} \boldsymbol{\beta}_{\boldsymbol{z}}\right)
$$

where $\Lambda(m) \equiv \exp (m) /[1+\exp (m)]$ is the logit function and $\boldsymbol{\beta}$ is a $(K \times 1)$ vector of parameters. In Equation (1) the vector of explanatory variables $\left(\mathbf{x}_{i}\right)$ is partitioned into focus $\left(\mathbf{f}_{i}\right)$ and control variables $\left(\mathbf{z}_{i}\right)$, that we discuss in detail in Sections 3.3 and 3.4. A set of robustness checks are presented in Section 5 .

\subsection{Focus variables}

The focus explanatory variables $\left(\mathbf{f}_{i}\right)$ in our analysis capture the two main forces that are expected to affect the probability of receiving an LHC-related order: firms' technological expertise and CERN's procurement rules.

CERN seeks firms able to successfully deliver the technologies it requires to advance the frontier of knowledge in particle physics. The ability of firms to satisfy the technical requirements of the tender is one of the pillars of CERN's procurement policy (see Section 2.3). We rely on a dummy variable that splits firms into hi- and lo-tech ("Hi-tech"). When firms register with the CERN procurement office they are assigned an activity code that identifies the product or service they are willing to supply. Following Castelnovo et al. (2018), we map these activity codes into a dichotomous variable used to identify firms that have registered to supply product or services deemed as hi-tech. Activity codes have been assigned to the following five categories by CERN experts:

1. most likely "off-the-shelf" orders of low technological intensity;

2. "off-the-shelf" orders with average technological intensity;

3. mostly "off-the-shelf" but usually hi-tech and requiring some careful specification;

4. hi-tech orders with moderate to high intensity of specification activity to customise products for the LHC;

5. products at the technological frontier, with intensive customisation and co-design involving CERN staff. 
Orders are deemed as hi-tech if they belong to categories 3-5. The "Hi-tech" variable equals one if a firm has registered for at least one order that experts at CERN have identified as as hi-tech. ${ }^{6}$ A firm's technological expertise has an impact on its ability to decode CERN's requirements and deliver to the expected standards. The CERN-supplier relationship can be referred to as a "dyad". If both parties of the dyad share high levels of technological expertise, learning processes and mutual understanding are enhanced (Autio et al., 2004). The construction of the LHC required the development of several new technologies, thus we expect hi-tech firms to have a comparative advantage over lo-tech competitors in becoming CERN's industrial partners.

Three variables related to procurement rules have been collected from CERN archives and databases. First, we consider the industrial return of each country to CERN's budget ("Ind. Ret."). This variable is captures CERN's implementation of the juste retour principle, according to which the aggregate value of contracts awarded to a MS should reflect its contribution to CERN's budget. The return coefficient of a MS is defined as the ratio between its percentage share of the value of all contracts over the preceding four years and its percentage contribution to the CERN Budget over the same period. CERN applies different return coefficients for supply and service contracts. Since we are not able to distinguish between these two types of contracts in our data, we rely on an average for supplies and services. Given that the return coefficient measures the value of contracts recently awarded to firms in a given MS weighted by its contribution to CERN's budget, we expect this variable to be positively associated with the probability of becoming a supplier.

However, CERN does not implement a strict juste retour policy which would imply a one to one relationship between contribution to the budget and value of contracts awarded. Rather, CERN aims to achieve a balanced industrial return for its MS: it "weighs" the percentage value of contracts awarded with the percentage contribution of each MS. If a MS is poorly balanced - provided that technical requirements are met - a set of correction mechanisms are activated to favor firms in those countries with the aim of improving the

\footnotetext{
${ }^{6}$ Examples of hi-tech items are magnets and radiofrequency cavities. Magnets are used to ensure that particles in the accelerator do not drift apart and are able to follow complex paths while maintaining speed. To accelerate particles, the accelerators are fitted with metallic chambers containing an electromagnetic field known as radiofrequency cavities. See: https://home.cern/science/engineering.
} 
Figure 4: Geographical distribution of firms: 1997-2007

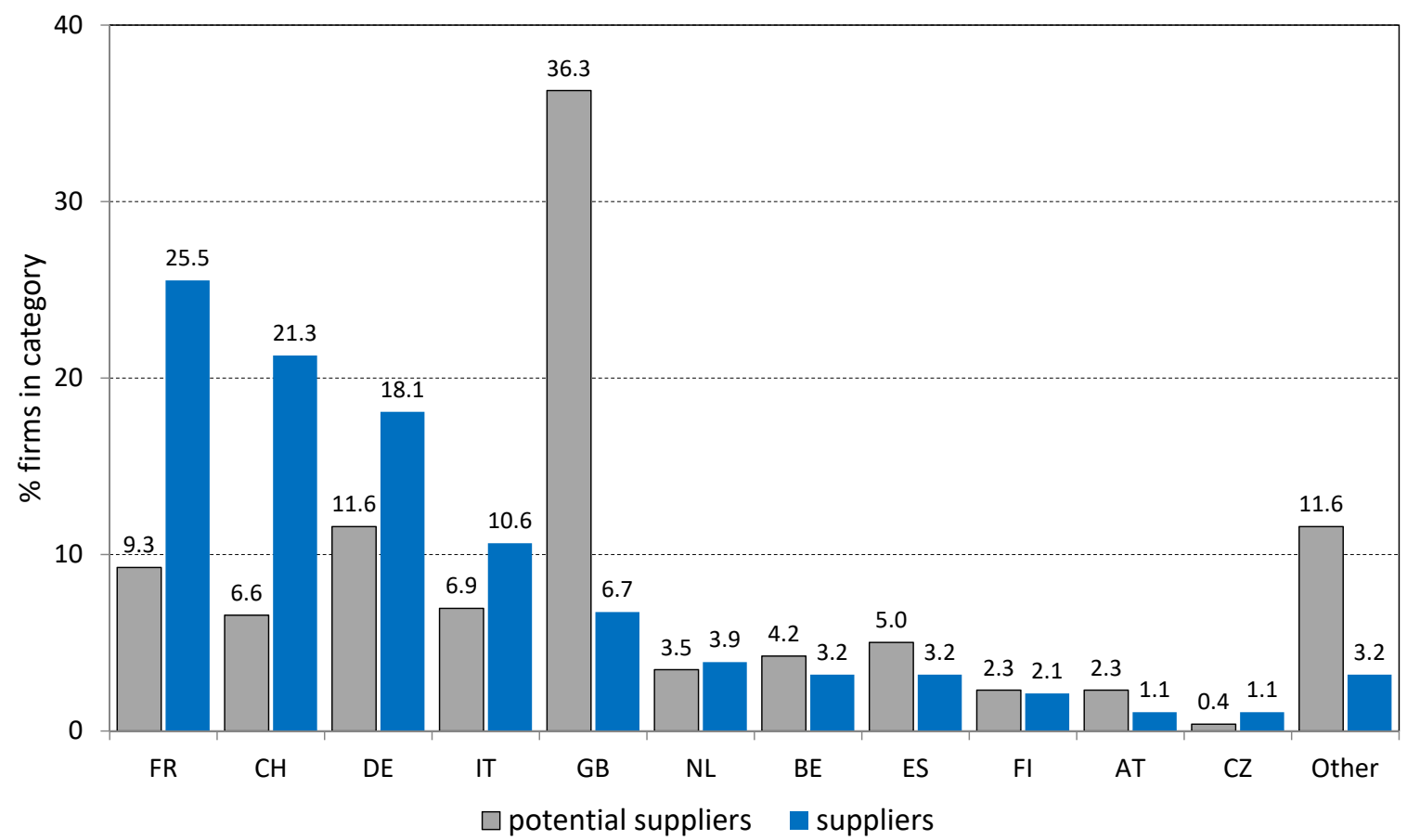

industrial return of that MS (see Section 2.3). To capture this aspect in our empirical model, we consider a dummy that characterizes the country as poorly or well balanced ("Poorly balanced"). We define a country as "poorly balanced" if its return coefficients for services and supplies are both below their respective threshold; the probability of supplying an LHC-related order is expected to be positively associated with this variable.

To account for possible spatial proximity effects, we also include a dummy variable ("Home") that takes on value one if a firm is located in France or Switzerland. Figure 4 shows that in the 1997-2007 period $46.8 \%$ of suppliers in our sample are located either in France or Switzerland. Interestingly, the existence of a premium in favor of French and Swiss firms has been documented as early as of 1992, with figures suggesting that France and Switzerland, while contributing to CERN's budget for $17 \%$ and $4 \%$, respectively, received contracts accounting for $33 \%$ and $24 \%$ of total orders (Rodgers, 1992).

The existence of a home premium in CERN procurement is consistent with several ex- 
planations. Breton and Salmon (1996) showed that governments may discriminate in favor of local suppliers because geographic proximity may reduce monitoring costs. A similar explanation is provided by Shingal (2015) who asserted that the existence of a home premium in public procurement can be related to minimizing average procurement costs due to asymmetric information. Other possible drivers are associated with the nature of the product or service under procurement; the number of domestic and international competitors in the specific market object of the contract; and practical considerations, including the language of the tender or the low value of the contract which might act as a deterrent for foreign firms. See also Williams (2014) and Brülhart and Trionfetti (2009).

We capture the time-varying nature of "Ind. Ret." and "Poorly balanced" considering the value of these variables for the year when firms registered for the first time in the CERN procurement database. This issue is further investigated in Section 5.5.

\subsection{Control variables}

We include a large set of control variables $\left(\mathbf{z}_{i}\right)$ to all our empirical models. We have retrieved information on firm size and primary NACE 2 digit activity code from the ORBIS database. Dichotomous variables classifying firms as large, medium or small enter the regression models as a set of size fixed effects ("Size FE"). ${ }^{7}$ Similarly, dichotomous variables are used to identify a firm's primary economic activity and enter the logit model as a set of sector fixed effects ("Sector FE").

As shown in Figure 3 both the number of actual and potential suppliers vary over time. These patterns are correlated with the schedule of the LHC program. Depending on the phases of the project's life cycle, there will be years with a higher (or lower) number of tenders and contracts awarded, which are independent of firms' characteristics or CERN's procurement policy. To capture these dynamics, we have constructed a set of dichotomous variables, one for each year in the 1997-2007 period ("Registration year FE"). Each of these binary variables equals one the year that the firm first registered to tender for an LHC contract and zero otherwise.

\footnotetext{
${ }^{7}$ In ORBIS firms are divided into four size categories: very large, large, medium or small. We bundle together ORBIS' very large and large categories.
} 
For each firm we also collect information on the number of orders they registered for, "log(no. orders)". This variable counts the number of applications by each firm in the database since its registration year. It captures different dimensions of a firm's relationship with CERN. If a firm applies several times in the procurement tendering procedure, it progressively gains understanding about the process and rules applied by CERN, thus increasing its knowledge and probability of success by means of experience (Tammi et al., 2014; Flynn and Davis, 2017). Moreover, a higher number of applications is expected to be associated with a decrease in cognitive distance between the potential supplier and CERN (Caloffi and Gambarotto, 2017). Both interpretations suggest a positive sign for the estimated coefficient on "log(no. orders)".

To further control for the fact that the longer a firm has been registered the more applications it has likely filed, thus leading to a higher probability of becoming a supplier, the number of years in the CERN database has been added. This variable ranges from 1 to 11 and is denoted as "Years in CERN DB".

\subsection{Research questions}

Having discussed CERN's procurement rules, as well as our data, we can illustrate our research questions and tightly link them to our empirical strategy:

$\mathcal{R} \mathcal{Q}_{1}$. Is the probability of becoming a supplier of the LHC project associated with firms' technological level?

$\mathcal{R} \mathcal{Q}_{2}$. Are political constraints important? If so, the probability of becoming a supplier of a the LHC project should also be associated with variables capturing CERN's procurement rules.

$\mathcal{R} \mathcal{Q}_{3}$. Is there a home premium in CERN's procurement? If so, being located in France and Switzerland should be associated with a higher probability of becoming a supplier of the LHC project.

$\mathcal{R} \mathcal{Q}_{4}$. What is the relative importance of technological factors and political constraints? 
Given the discussion in previous Sections, our expectations on estimated coefficients are the following. With respect to $\mathcal{R} \mathcal{Q}_{1}$, we expect the coefficient on "Hi-tech" to be positive (Autio et al., 2004). Considering $\mathcal{R} \mathcal{Q}_{2}$ we expect the coefficients on "Ind. Ret." and "Poorly balanced" to be both positive, since political constraints affecting CERN's procurement rules will be positively associated with a firm's probability of initiating a supplier relationship (Åberg and Bengtson, 2015). A specific aspect, unrelated to technological or cost features of the contracts, is the existence of a possible home premium, summarized by the dichotomous variable "Home" in the set of focus variables. The literature and the previous empirical evidence discussed in Section 3.3 lead us to expect, for $\mathcal{R} \mathcal{Q}_{3}$, the existence of a home premium affecting CERN procurement. As for $\mathcal{R} \mathcal{Q}_{4}$, since CERN does not implement a strict juste retour policy and is a mission-oriented organization (Florio et al., 2018b), whose main goal is to push the frontier of research in particle physics, we expect that ensuring that the technical requirements of the contract are met should have a priority over the political constraints to its procurement activity.

\section{Results}

\subsection{Descriptive Statistics}

Table 1 shows the sample average of the main explanatory variables considered in our regression models dividing firms into LHC potential and actual suppliers. The last column of the table reports $p$-values for the two-sided null hypothesis that means are equal across the two groups..$^{8}$

As we can see potential suppliers and LHC suppliers do not show any statistically significant difference for what concerns the proportion of firms in each size class or in terms of the hi-tech classification. In fact, the percentage of hi-tech firms is $46 \%$ for potential suppliers and $47 \%$ for suppliers. The second and third row of Table 1 show that while suppliers' host country on average have a higher industrial return, a higher percentage of potential suppliers

\footnotetext{
${ }^{8}$ Some of the continuous variables in our dataset feature an asymmetric distribution (i.e. "Ind. Ret.", " $\log ($ no. orders)"), therefore we have also run the analysis relying on the sample median. Results are unaffected. We thank an anonymous reviewer for this suggestion.
} 
Table 1: Sample average of variables for suppliers and potential suppliers

\begin{tabular}{c|lccl}
\hline \multicolumn{2}{l}{ Variable } & Potential Supplier & Supplier & $p$-value \\
\hline \multirow{5}{*}{} & Hi-tech (\%) & 46.33 & 47.16 & 0.8469 \\
& Ind. Ret. $(\mathrm{t}=0)$ & 0.95 & 1.71 & $0.0000^{* * *}$ \\
& Poorly balanced (t=0) $(\%)$ & 29.73 & 18.44 & $0.0022^{* * *}$ \\
& Home (\%) & 15.83 & 46.81 & $0.0000^{* * *}$ \\
\hline \multirow{5}{*}{ Small (\%) } & 28.96 & 23.05 & 0.1186 \\
& Medium (\%) & 35.91 & 37.59 & 0.6859 \\
& Large (\%) & 24.32 & 26.60 & 0.5452 \\
& Very Large (\%) & 10.81 & 12.77 & 0.4814 \\
& Years in CERN DB & 6.00 & 7.22 & $0.0000^{* * *}$ \\
& $\log ($ no. orders) & 1.05 & 1.32 & $0.0001^{* * *}$ \\
\hline
\end{tabular}

Notes: the table shows the sample average for each focus $\mathbf{f}_{i}$ and control $\mathbf{z}_{i}$ variable in the first column. The last column shows the two-sided $p$-value for the null hypothesis equal of means allowing for unequal variances between the two groups. A low $p$-value provides empirical evidence against the null hypothesis.

are located in poorly balanced countries. In both cases, the difference in mean is statistically significant at the 0.01 level. The fact that a higher percentage of potential suppliers is hosted in poorly balanced countries might signal that, given that CERN implements measures to provide a well balanced return coefficient to the MS firms belong to, there is an incentive for firms in those countries to apply for an order.

Descriptive statistics also highlight that suppliers tend to be in the CERN procurement database for a longer time period and have also registered for more orders than potentials suppliers (4 versus 3 orders on average). Moreover, looking at the fourth row of Table 1, we see that a much higher percentage of suppliers, $46.81 \%$, is located either in Switzerland or France. The difference in mean for these three variables is statistically significant at the 0.01 level.

\subsection{Main Results}

Table 2 shows estimates of the logit model in Equation (1). We consider three specifications that differ according to which of the focus variables are included in the model; moreover, we note that the same set of control variables is included in all models. All inferences are based on the heteroscedasticity-consistent estimator of the covariance matrix, due to White (1980), to capture the effects of firms' unobserved and unmodeled heterogeneity.

We begin from the assessment of whether becoming a supplier is more likely for firms 
providing CERN with hi-tech expertise and solutions $\left(\mathcal{R} \mathcal{Q}_{1}\right)$. To this end, we note that the coefficient on the indicator variable "Hi-tech" is positive and statistically different from zero at the 0.01 significance level in all specifications. This supports the fact that, as documented by Vuola and Hameri (2006), the amount of hi-tech knowledge and expertise should increase the probability of becoming a supplier. Interestingly, the magnitude of the coefficient on "Hi-tech" does not vary much across specifications.

We now focus on the relative weight of CERN's procurement principles in determining the probability that a firm becomes a supplier, alongside with firms' technological expertise examined above $\left(\mathcal{R} \mathcal{Q}_{2}\right)$. To this end, we consider the value of contracts recently awarded to firms in a given MS weighted by its contribution to CERN's budget, that is the coefficient on "Ind. Ret.", that enters all specifications. Chances are that, ceteris paribus, firms belonging to MS with high industrial return will be more likely to obtain the deal with respect to firms hosted in a country with a low industrial return. This is part of CERN's overall procurement policy, given that - as discussed above in Section 2.3 - it is an international venture based on the monetary contributions of its MS. Columns (1-3) of Table 2 show that, as expected, the probability of becoming CERN's industrial partners is positively associated with the industrial return the MS that hosts the firm. The coefficient on "Ind. Ret." is statistically significant at the $1 \%$ level in $\mathcal{M}_{1}$ and $\mathcal{M}_{2}$, while it is much smaller and statistically not distinguishable from zero in $\mathcal{M}_{3}$, when "Home" is added to the model.

As a way of enforcing the juste retour principle, CERN implements a set of procurement rules - such as limited tendering, alignment and splitting rules - with the aim of improving the return coefficient of its poorly balanced MS. To capture the role of these rules in determining the probability of becoming a supplier of CERN, in model $\mathcal{M}_{2}$ we interact "Ind. Ret." with the indicator variable "Poorly balanced", that takes on unit value if the firm's home country is poorly balanced and zero otherwise. Because of the enforcement of a set of rules aimed at improving the return coefficient in poorly balanced countries, we expect a positive sign on the coefficient of this interaction term. ${ }^{9}$

\footnotetext{
${ }^{9}$ There are two reasons for considering an interaction term. First, it captures the fact that the association between "Ind. Ret." and the probability of becoming a supplier is expected to be different in poorly or well balanced MS. Second, whether a MS is poorly balanced depends on "Ind. Ret." being below a threshold value. We have estimated also two alternative specifications of $\mathcal{M}_{2}$. In the first, we added to $\mathcal{M}_{1}$ "Poorly
} 
Table 2: Logit models: factors affecting the probability of becoming LHC supplier

\begin{tabular}{lccc}
\hline & $(1)$ & $(2)$ & $(3)$ \\
& $\mathcal{M}_{1}$ & $\mathcal{M}_{2}$ & $\mathcal{M}_{3}$ \\
\hline Hi-tech & $0.411^{*}$ & $0.408^{*}$ & $0.480^{* *}$ \\
& $(0.215)$ & $(0.216)$ & $(0.219)$ \\
Ind. Ret. (t=0) & $0.652^{* * *}$ & $0.661^{* * *}$ & 0.175 \\
& $(0.108)$ & $(0.117)$ & $(0.150)$ \\
Ind. Ret. $\times$ Poorly Bal. (t=0) & & 0.157 & \\
& & $(0.678)$ & \\
Home & & & $1.578^{* * *}$ \\
& & & $(0.435)$ \\
Years in CERN DB & & & $0.401^{* * *}$ \\
& $(0.150)$ & $0.394^{* * *}$ & $(0.146)$ \\
log(no. orders) & & $(0.150)$ & $0.625^{* * *}$ \\
& $\left(0.1370^{* * *}\right.$ & $0.569^{* * *}$ & $(0.141)$ \\
\hline Size FE & & $(0.131)$ & $\checkmark$ \\
Sector FE & $\checkmark$ & $\checkmark$ & $\checkmark$ \\
Registration year FE & $\checkmark$ & $\checkmark$ & $\checkmark$ \\
\hline N & 541 & $\checkmark$ & 541 \\
\hline
\end{tabular}

Notes: heteroscedasticity-consistent standard errors in parentheses; "** $p$-value $<0.10$, "**" $p$-value $<0.05$, "***" $p$-value $<$ 0.01 ; "N" is the number of observations. We included sets of dichotomous variables corresponding to size of firms ("Size FE"), two-digits NACE codes are included ("Sector FE") and year of registration with CERN ("Registration year FE").

While the estimated sign is consistent with this prediction, the impact of the interaction with "Poorly balanced" is not statistically distinguishable from zero. A possible explanation is that this rule applies only to contracts above a certain monetary value, and depends on whether the contract is for "services" or "supplies". Moreover, we are considering only a sub-sample of all CERN's suppliers, namely those that contributed to the construction of the LHC. It might well be that compliance with political constraints is done within the whole universe of suppliers (see Section 2.3).

Lastly, to provide an answer to $\mathcal{R} \mathcal{Q}_{3}$, the variable "Home" enters $\mathcal{M}_{3}$ to control for the existence of localized effects in the choice of suppliers (Williams, 2014) and verify whether Swiss and French firms have a greater chance of becoming suppliers (see Figure 4). Notice that, since Switzerland and France are always well balanced, we cannot simultaneously balanced" as an intercept shifter, without the interaction term; in the second, we included both this intercept shifter and the interaction between "Poorly balanced" and "Ind. Ret.". In all cases, the effect of "Poorly balanced" is statistically indistinguishable from zero. Results are available upon request from the authors. 
include "Home" and "\% Poorly balanced". An increase in the probability of securing an order for firms in CERN's host countries - that we refer to as home premium - could reflect the fact that geographical proximity facilitates monitoring, as well as communications and interactions with CERN offices due to language and cultural factors. Moreover, geographical proximity can also reduce the costs of procurement, including search and monitoring costs. We do find evidence of a home premium: the estimated coefficient on "Home" is positive and statistically significant at the 0.01 level. The inclusion of this variable makes the coefficient on "Ind. Ret." statistically not distinguishable from zero. This is explained by the fact that the highest average values of "Ind. Ret." are recorded for Switzerland and France.

We now turn to control variables, $\mathbf{z}_{i}$. We see that, as expected, the estimated coefficient on "Years in CERN DB" is positive and statistically significant at the 0.01 level, thus suggesting that the longer a firm has been registered in the CERN database, the higher the likelihood of becoming a supplier. A similar effect is captured by "log(no. orders)": the coefficient on this variable is also positive and statistically distinguishable from zero at the 0.01 level. This is in line with Tammi et al. (2014) who suggested that the ability of firms to gather relevant information and use it to increase their knowledge of the tenders is associated with higher bidding activity. Flynn and Davis (2017) refer to this aspect as "procedural capability", showing that it has a significant effect on the number of tenders submitted and ultimately on the contracts obtained. Also, a higher number of applications increases a firm's chance to interact directly with CERN officials and to make itself known, thus increasing reciprocal knowledge. This aspect can also be seen as an increase in a firm's relational capability (Flynn and Davis, 2017).

As an additional control, we have considered the firms' size. With respect to size, the literature has shown that smaller firms are at a disadvantage with respect to larger firms in obtaining contracts (see e.g. Flynn et al., 2015). A joint test of hypothesis reveals that coefficients on "Size FE" are statistically not distinguishable from zero.

Sector fixed effects based on 2-digit NACE codes have also been included in all models to control for the fact that there might be a pattern relating the probability of becoming a supplier and the activities and services provided by the firms which, in turn, depend on their sector of activity. 
We have also added variables for each firm's year of registration to control for the number of firms that register each year. These variables also control for the possibility that there might be a pattern relating the phases of the LHC project's life cycle to the probability of receiving an order. In fact, Figure 3 reveals that there are years with a higher (or lower) number of tenders and contracts awarded, which are independent of firms characteristics or CERN's procurement policy. A joint test of hypothesis reveals that coefficients on "Registration year FE" are statistically distinguishable from zero.

\subsection{On the relative importance of technological factors and polit- ical constraints}

In order to compare the relative weight of technological factors and political constraints $\left(\mathcal{R} \mathcal{Q}_{4}\right)$, we consider the fitted values from our models. Figure 5 provides a rough quantitative assessment of how technological and political factors affect the probability that firms start collaborating with CERN. We plot the change in fitted probabilities $\left(\Delta \widehat{\operatorname{Pr}}\left(y_{i}=1 \mid \mathbf{x}_{i}\right)\right)$ derived from models $\mathcal{M}_{2}$ and $\mathcal{M}_{3}$ in Table 2. Each panel shows the change in the estimated probability conditional on the explanatory variables taking on different values.

The two graphs in the top panel are based on estimates from $\mathcal{M}_{2}$. The fitted probability in well balanced countries is $63.13 \%$ for hi-tech firms and $53.23 \%$ for lo-tech firms. In poorly balanced countries these fitted probabilities equal $66.70 \%$ and $57.11 \%$ for hi- and lo-tech firms, respectively. The top-left panel shows what we refer to as "technological premium" for firms in well and poorly balanced countries. The height of the leftmost (gray) bar in this plot is $9.90 \%$ and represents the increase in the fitted probability due to being a hi-tech firm in a well balanced country with respect to being lo-tech in the same country. In poorly balanced countries this estimate is $9.59 \%$, thus suggesting that the "technological premium" is higher in well balanced countries. 
Figure 5: Change in fitted probability from $\mathcal{M}_{2}$ and $\mathcal{M}_{3}$
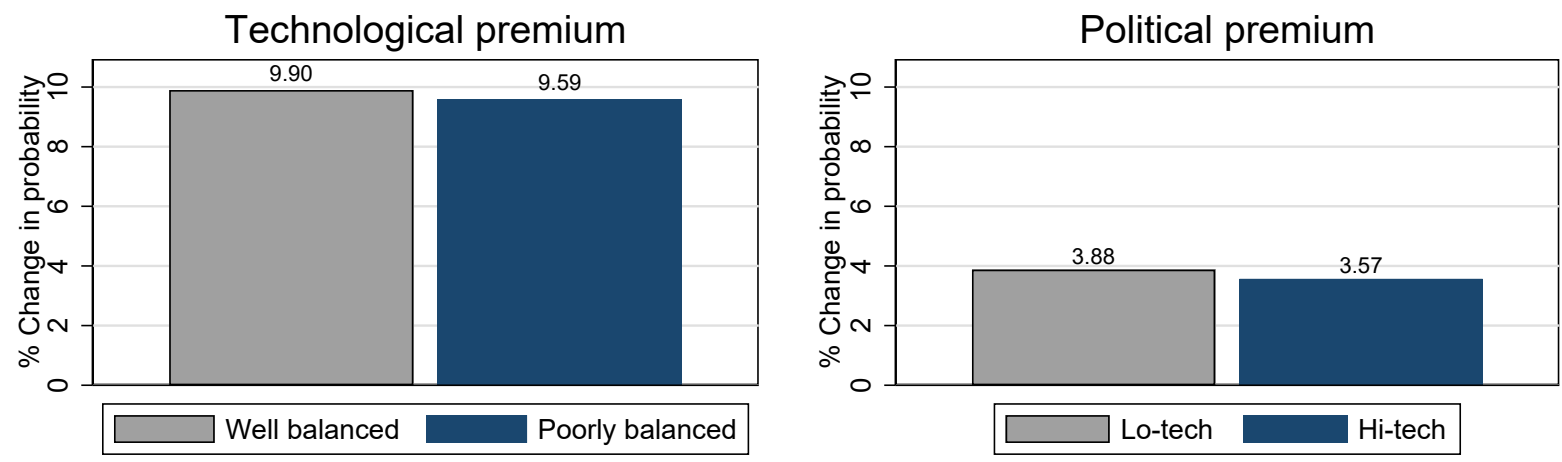

(a) $\Delta \widehat{\operatorname{Pr}}\left(y_{i}=1 \mid \mathbf{x}_{i}\right)$ from $\mathcal{M}_{2}$
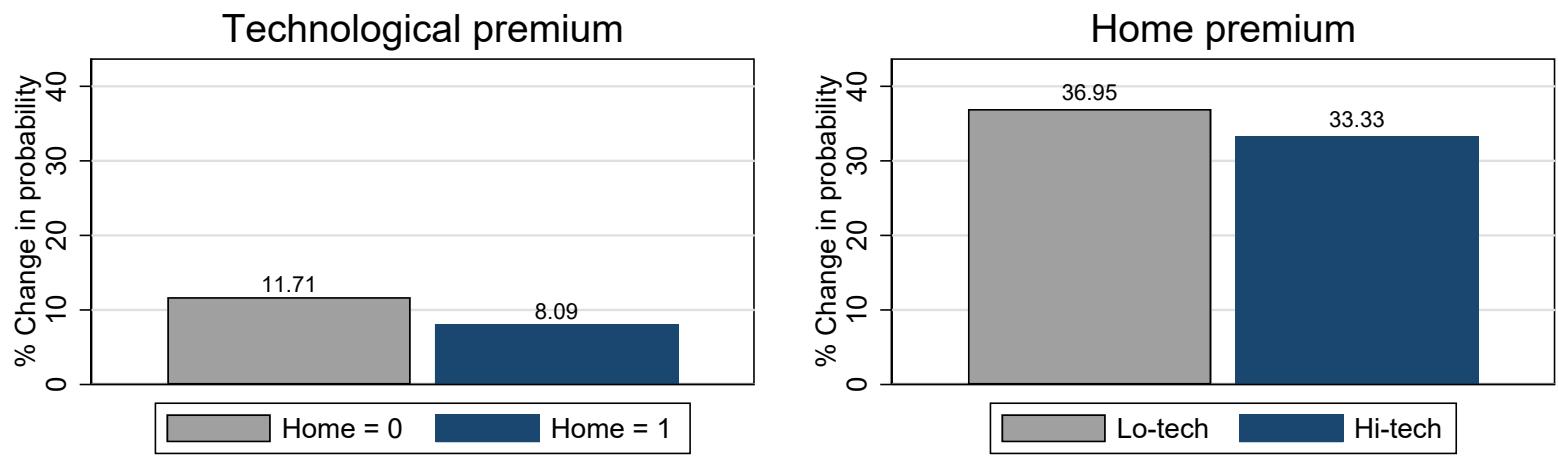

(b) $\Delta \widehat{\operatorname{Pr}}\left(y_{i}=1 \mid \mathbf{x}_{i}\right)$ from $\mathcal{M}_{3}$

Notes: the figures show the variation in fitted probabilities $\left(\Delta \widehat{\operatorname{Pr}}\left(y_{i}=1 \mid \mathbf{x}_{i}\right)\right)$ conditional on explanatory variables taking on different values. The two graphs in the top (bottom) panel are based on model $\mathcal{M}_{2}\left(\mathcal{M}_{3}\right)$. The top-left panel shows $\widehat{\operatorname{Pr}}\left(y_{i}=1 \mid \mathbf{x}_{i}\right)$ for hi-tech firms in well-balanced (gray bar) and poorly-balanced countries (blue bar). The top-right panel shows $\widehat{\operatorname{Pr}}\left(y_{i}=1 \mid \mathbf{x}_{i}\right)$ for hi-tech (gray bar) and lo-tech firms (blue bar) in poorly-balanced countries. The bottom-left panel shows $\widehat{\operatorname{Pr}}\left(y_{i}=1 \mid \mathbf{x}_{i}\right)$ for hi-tech firms not hosted in France or Switzerland (gray bar; Home=0) and for those located in France or Switzerland (blue bar; Home=1). The bottom-right panel shows $\widehat{\operatorname{Pr}}\left(y_{i}=1 \mid \mathbf{x}_{i}\right)$ for hi-tech (gray bar) and lo-tech firms in France or Switzerland (blue bar). The remaining explanatory variables are set equal to their sample average if continuous or equal to zero if dichotomous.

The top-right panel shows what we refer to as "political premium" for hi- and lo-tech firms. This is an estimate of $\Delta \widehat{\operatorname{Pr}}\left(y_{i}=1 \mid \mathbf{x}_{i}\right)$ associated with being hosted in a poorly balanced country compared to being hosted in a well balanced country. As we can see, the "political premium" is equal to $3.88 \%$ and to $3.57 \%$ for lo- and hi-tech firms, respectively. This suggests that the "political premium" is higher for lo-tech firms. Moreover, comparison of the two plots in the top of Figure 5 highlights that, consistently with CERN's procurement principles, technical requirements have a priority over providing a well balanced return to its MS; in fact, the estimated "political premium" is much lower that the estimated "technological premium". 
The two graphs in the bottom panel are instead based on estimates from $\mathcal{M}_{3}$. The fitted probability of providing an LHC-related order for firms located outside France and Switzerland is $48.97 \%$ if these are hi-tech and $37.26 \%$ if these are lo-tech. In France or Switzerland these fitted probabilities increase to $82.30 \%$ and $74.21 \%$ for hi- and lo-tech firms, respectively. The bottom-left panel shows that the estimated "technological premium" from $\mathcal{M}_{3}$ is $8.09 \%$ for firms in France or Switzerland and is $11.71 \%$ for firms located elsewhere. Moving to the bottom-right graph, we see that the height of the leftmost (gray) bar in this plot is $36.95 \%$; this represents the increase in the fitted probability due to being a lo-tech firms hosted in France or Switzerland with respect to being lo-tech in other MS. For hi-tech firms this estimate is $33.33 \%$, thus suggesting that the home premium is higher for lo-tech firms.

Overall, estimates of the technological premium - suggesting a higher probability of becoming CERN suppliers for hi-tech than lo-tech firms - are similar across models: these range from $8.09 \%$ to $11.71 \%$. Interestingly, the contribution of correction mechanisms aimed at favoring firms in poorly balanced MS seems to be more important for lo-tech firms than for hi-tech firms. This can be explained recalling that one of CERN's procurement principle - and possibly the most relevant, given the its mission-oriented nature Florio et al. (2018b) - is to ensure that the technical requirements of the contract are met. Moreover, it is also possible that the less specific is the product required by CERN, the easier it is to implement correction mechanisms aimed at favoring firms in poorly balanced countries and the larger is the pool of firms that can deliver that order. This would also explain why we report a larger home premium for lo-tech than for hi-tech firms. Last, but not least, when focusing on Figure 5b we can see that the contribution of the home premium is much larger than that of the technological premium. On the contrary, Figure 5a highlights that the technological premium is associated with a higher increase in probability of becoming a supplier than the political premium. 


\section{$5 \quad$ Additional results and robustness checks}

\subsection{Exclusion of host countries}

As shown in Figure 4, firms hosted at the Swiss-French border near CERN's facilities make up $45.8 \%$ of suppliers. Interestingly, in the years for which we have data, both countries are always characterized as being well balanced and have the some of the highest industrial returns. Furthermore, Swiss and French firms might in general benefit from a positive home premium, as documented in Section 4.2. Firms located in Switzerland and France may thus follow different strategies and exhibit different behavior in their tendering activities with respect to firms hosted in other MS.

To verify the extent to which these factors might influence our results, in columns 2 and 4 of Table 3 we have excluded Swiss and French firms from the sample used to estimate $\mathcal{M}_{1}$ and $\mathcal{M}_{2}$, respectively. Overall, results are confirmed with three interesting qualifications. First, possibly due to the reduction in sample size that tends to magnify the estimated standard errors, the estimated coefficients on "Hi-tech" in columns 2 and 4 retain the positive sign but become not statistically distinguishable from zero at any conventional level. Second, in both cases the coefficients on "Ind. Ret." increase. Third, in column 4 the estimated coefficient on the interaction term is positive and larger than in the baseline specification in column 3 . This result could be driven by the fact that, once firms from home countries, which might have an advantage related to a proximity premium, are excluded, the correcting mechanism aimed at favoring firms in poorly balanced countries becomes more relevant.

\subsection{Who is driving the home premium? Who is gaining from it?}

Up to now we have never attempted to disentangle whether the home premium is driven by the French or Swiss firms in our sample. We investigate this issue in column 6 of Table 3, where in model $\mathcal{M}_{3}$ "Home" is replaced by two dichotomous variables that identify firms in France and Switzerland. As we can see, the main results are unchanged, however we can now highlight that the home premium seems to be primarily driven by firms in France.

A related question, investigated in columns 7 and 8 , is whether all firms enjoy equal 
Table 3: Logit models - more on the home bias

\begin{tabular}{|c|c|c|c|c|c|c|c|c|}
\hline & $\begin{array}{l}(1) \\
\mathcal{M}_{1}\end{array}$ & $\begin{array}{c}(2) \\
\mathcal{M}_{1}^{\text {no Home }} \\
\end{array}$ & $\begin{array}{l}(3) \\
\mathcal{M}_{2}\end{array}$ & $\begin{array}{c}(4) \\
\mathcal{M}_{2}^{\text {no Home }} \\
\end{array}$ & $\begin{array}{l}(5) \\
\mathcal{M}_{3}\end{array}$ & $\mathcal{M}_{3}^{\mathrm{CH}, \mathrm{FR}}$ & $\begin{array}{c}(7) \\
\mathcal{M}_{3}^{\text {lo-tech }} \\
\end{array}$ & $\mathcal{M}_{3}^{\text {hi-tech }}$ \\
\hline Hi-tech & $\begin{array}{l}0.411^{*} \\
(0.215)\end{array}$ & $\begin{array}{c}0.419 \\
(0.273)\end{array}$ & $\begin{array}{l}0.408^{*} \\
(0.216)\end{array}$ & $\begin{array}{c}0.410 \\
(0.275)\end{array}$ & $\begin{array}{l}0.480^{* *} \\
(0.219)\end{array}$ & $\begin{array}{l}0.482^{* *} \\
(0.218)\end{array}$ & & \\
\hline Ind. Ret. $(\mathrm{t}=0)$ & $\begin{array}{l}0.652^{* * *} \\
(0.108)\end{array}$ & $\begin{array}{l}{ }^{*} 0.886^{*} \\
(0.486)\end{array}$ & $\begin{array}{l}0.661^{* * *} \\
(0.117)\end{array}$ & $\begin{array}{l}* 1.295^{* *} \\
(0.593)\end{array}$ & $\begin{array}{l}0.175 \\
(0.150)\end{array}$ & $\begin{array}{c}0.434 \\
(0.362)\end{array}$ & $\begin{array}{c}0.161 \\
(0.194)\end{array}$ & $\begin{array}{l}0.757^{*} \\
(0.408)\end{array}$ \\
\hline $\begin{array}{l}\text { Ind. Ret. } \\
\times \text { Poorly Bal. }(t=0)\end{array}$ & & & $\begin{array}{l}0.157 \\
(0.678)\end{array}$ & $\begin{array}{c}1.228 \\
(0.840)\end{array}$ & & & & \\
\hline Home & & & & & $\begin{array}{l}1.578^{* * *} \\
(0.435)\end{array}$ & & $\begin{array}{c}1.795^{* * *} \\
(0.598)\end{array}$ & $\begin{array}{c}1.178 \\
(0.739)\end{array}$ \\
\hline $\mathrm{CH}$ & & & & & & $\begin{array}{c}0.549 \\
(1.341)\end{array}$ & & \\
\hline FR & & & & & & $\begin{array}{c}1.352^{* * *} \\
(0.503)\end{array}$ & & \\
\hline Years in CERN DB & $\begin{array}{l}0.395^{* * *} \\
(0.150)\end{array}$ & $\begin{array}{l}{ }^{*} 0.332^{* *} \\
(0.137)\end{array}$ & $\begin{array}{l}0.394^{* * *} \\
(0.150)\end{array}$ & $\begin{array}{l}{ }^{*} 0.319^{* *} \\
(0.138)\end{array}$ & $\begin{array}{l}0.401^{* * *} \\
(0.146)\end{array}$ & $\begin{array}{c}* 0.400^{* * *} \\
(0.146)\end{array}$ & $\begin{array}{c}0.204 \\
(0.139)\end{array}$ & $\begin{array}{c}0.830 \\
(1.388)\end{array}$ \\
\hline $\log$ (no. orders) & $\begin{array}{l}0.570^{* * *} \\
(0.131)\end{array}$ & $\begin{array}{c}{ }^{*} 0.730^{* * * *} \\
(0.157)\end{array}$ & $\begin{array}{l}0.569^{* * *} \\
(0.131)\end{array}$ & $\begin{array}{c}{ }^{*} 0.732^{* * *} \\
(0.157)\end{array}$ & $\begin{array}{l}0.625^{* * *} \\
(0.141)\end{array}$ & $\begin{array}{c}{ }^{*} 0.628^{* * *} \\
(0.142)\end{array}$ & $\begin{array}{c}0.535^{* * *} \\
(0.189)\end{array}$ & $\begin{array}{c}0.984^{* * *} \\
(0.283)\end{array}$ \\
\hline Size FE & $\checkmark$ & $\checkmark$ & $\checkmark$ & $\checkmark$ & $\checkmark$ & $\checkmark$ & $\checkmark$ & $\checkmark$ \\
\hline Sector FE & $\checkmark$ & $\checkmark$ & $\checkmark$ & $\checkmark$ & $\checkmark$ & $\checkmark$ & $\checkmark$ & $\checkmark$ \\
\hline Registration year FE & $\checkmark$ & $\checkmark$ & $\checkmark$ & $\checkmark$ & $\checkmark$ & $\checkmark$ & $\checkmark$ & $\checkmark$ \\
\hline $\mathrm{N}$ & 541 & 364 & 541 & 364 & 541 & 541 & 264 & 215 \\
\hline
\end{tabular}

Notes: see notes to Table $2 . \mathcal{M}_{j}^{\text {no Home }}$ for $j=1,2$ indicates that the model has been estimated after omitting French and Swiss firms. $\mathcal{M}_{3}^{\text {lo-tech }}\left(\mathcal{M}_{3}^{\text {lo-tech }}\right)$ denotes that the sample includes only lo-tech (hi-tech) firms.

benefits from the existence of an home premium. To answer this question, we have estimated $\mathcal{M}_{3}$ separately for hi- and lo-tech firms. As we can see from the last two columns of Table 3, the coefficient on "Home" is positive on both samples, but it is statistically distinguishable from zero only for lo-tech firms, confirming the results in Section 4.3. 


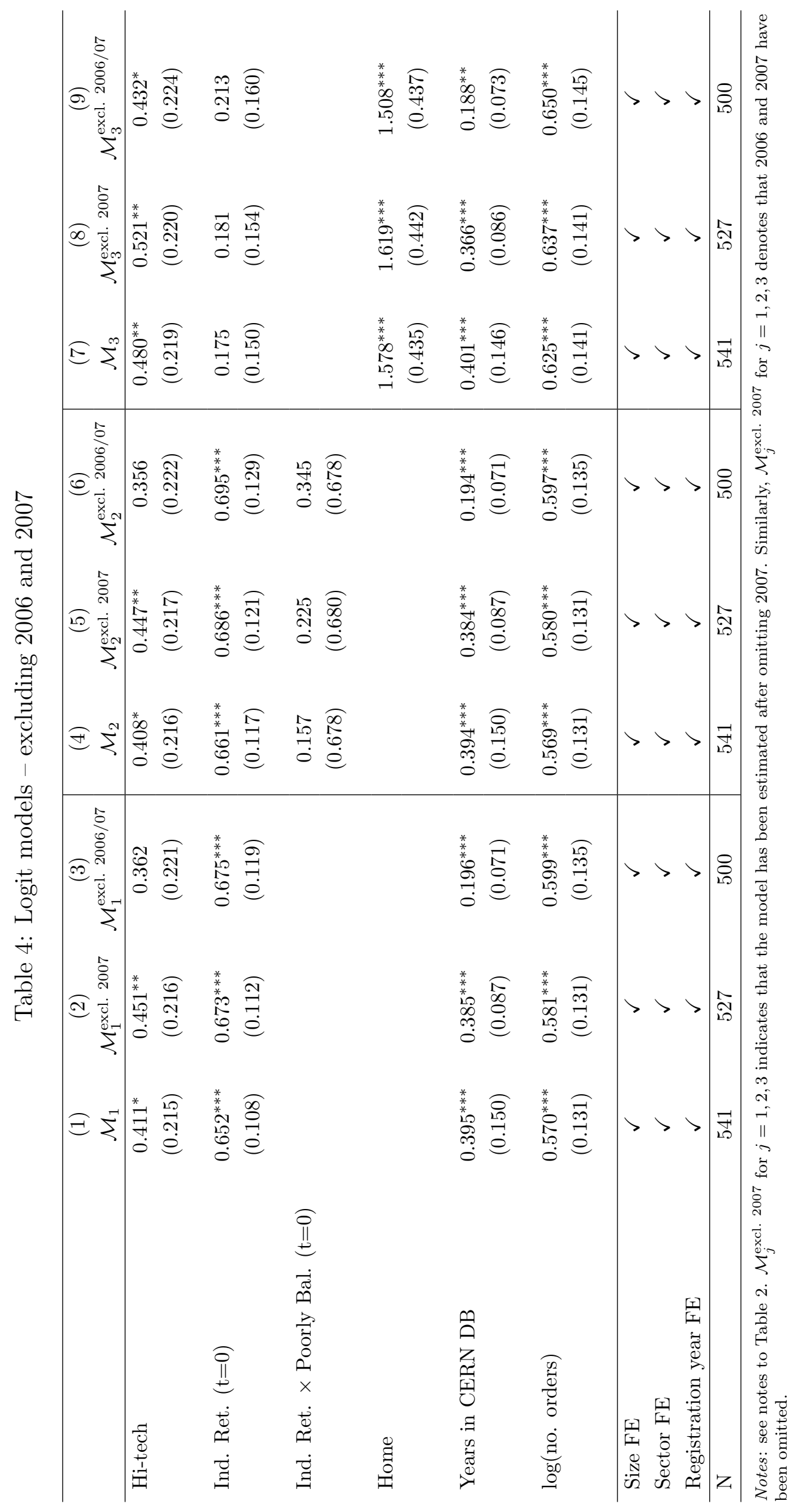


Table 5: Probit models: factors affecting the probability of becoming LHC supplier

\begin{tabular}{lccc}
\hline & $(1)$ & $(2)$ & $(3)$ \\
& $\mathcal{M}_{1}^{\text {Probit }}$ & $\mathcal{M}_{2}^{\text {Probit }}$ & $\mathcal{M}_{3}^{\text {Probit }}$ \\
\hline Hi-tech & $0.260^{* *}$ & $0.258^{* *}$ & $0.294^{* *}$ \\
& $(0.127)$ & $(0.128)$ & $(0.128)$ \\
Ind. Ret. (t=0) & $0.380^{* * *}$ & $0.385^{* * *}$ & 0.114 \\
& $(0.057)$ & $(0.062)$ & $(0.085)$ \\
Ind. Ret. $\times$ Poorly Bal. (t=0) & & 0.093 & \\
& & $(0.404)$ & \\
Home & & & $0.905^{* * *}$ \\
& & & $(0.243)$ \\
Years in CERN DB & & & $0.199^{* * *}$ \\
& $\left(0.202^{* * *}\right.$ & $0.201^{* * *}$ & $(0.071)$ \\
log(no. orders) & $(0.069)$ & $(0.069)$ & $0.372^{* * *}$ \\
& $(0.077)$ & $0.346^{* * *}$ & $(0.080)$ \\
\hline Size FE & $\checkmark$ & $(0.077)$ & $\checkmark$ \\
Sector FE & $\checkmark$ & $\checkmark$ & $\checkmark$ \\
Registration year FE & $\checkmark$ & $\checkmark$ & $\checkmark$ \\
\hline N & 541 & $\checkmark$ & 541 \\
\hline
\end{tabular}

Notes: see notes to Table 2.

\subsection{Exclusion of 2006-2007}

Inspection of Figure 3 highlights that, due to the completion of the construction phase, LHC suppliers drop dramatically in number at the end of the sampling period. On the contrary, potential suppliers do not experience a similar sharp drop. Thus, as a robustness check, we exclude first 2007, then also 2006 from each model. Our baseline results are confirmed in terms of sign, magnitude and largely also in terms of statistical significance of the estimated coefficients when 2007 is excluded. A noticeable difference is the reduction of the coefficient on "Hi-tech", that in the case of $\mathcal{M}_{1}$ and $\mathcal{M}_{2}$ becomes also statistically not distinguishable from zero, when 2006 and 2007 are excluded. This might signal that near the completion of the construction phase of the LHC programme all hi-tech orders had already been completed. 


\subsection{Probit models}

Results in Section 4.2 rely on a logit model. As a further robustness check, Table 5 shows estimates of probit models, that is we substitute the logit function $\Lambda(z)$ with the standard normal cumulative distribution function in Equation (1). Results in Table 5 highlight that our results are not affected by the selection of probit model in place of a logit model.

\subsection{Lagged values}

As shown in Figure 6(b) there seems to be a temporal pattern linking the date when a MS is declared poorly balanced and the number of firms that register in the CERN procurement database. More precisely, the percentage of both potential suppliers and LHC suppliers in poorly balanced MS is highest two years before the registration in the CERN procurement database. On the contrary, Figure 6(a) highlights that the average industrial return is highest the year the firm registered with CERN.

Because of lags between the date of the registration and the date when the tender is awarded, the probability of becoming a suppliers might depend not on the status of the MS the year the firm registered with the CERN Procurment Office but on the country's industrial return and status in previous years. If this were the case, we might observe a positive association between the probability of becoming supplier and the status of the country in earlier periods. To investigate this issue columns 2 and 3 of Table 6 report estimates of model $\mathcal{M}_{2}$ after assigning to "Poorly balanced" unit value if the country was poorly balanced one or two years before a firm registered with CERN and zero otherwise. Similarly, we consistently change the value of "Ind. Ret.". While our main conclusions are unaffected, the magnitude of the estimated coefficient on the interaction between "Ind. Ret." and "Poorly balanced" increases when moving from column 1 to column 3. Nevertheless, also in this case, the estimates are never statistically distinguishable from zero. 
Figure 6: Average industrial return and firms in poorly balanced Member States
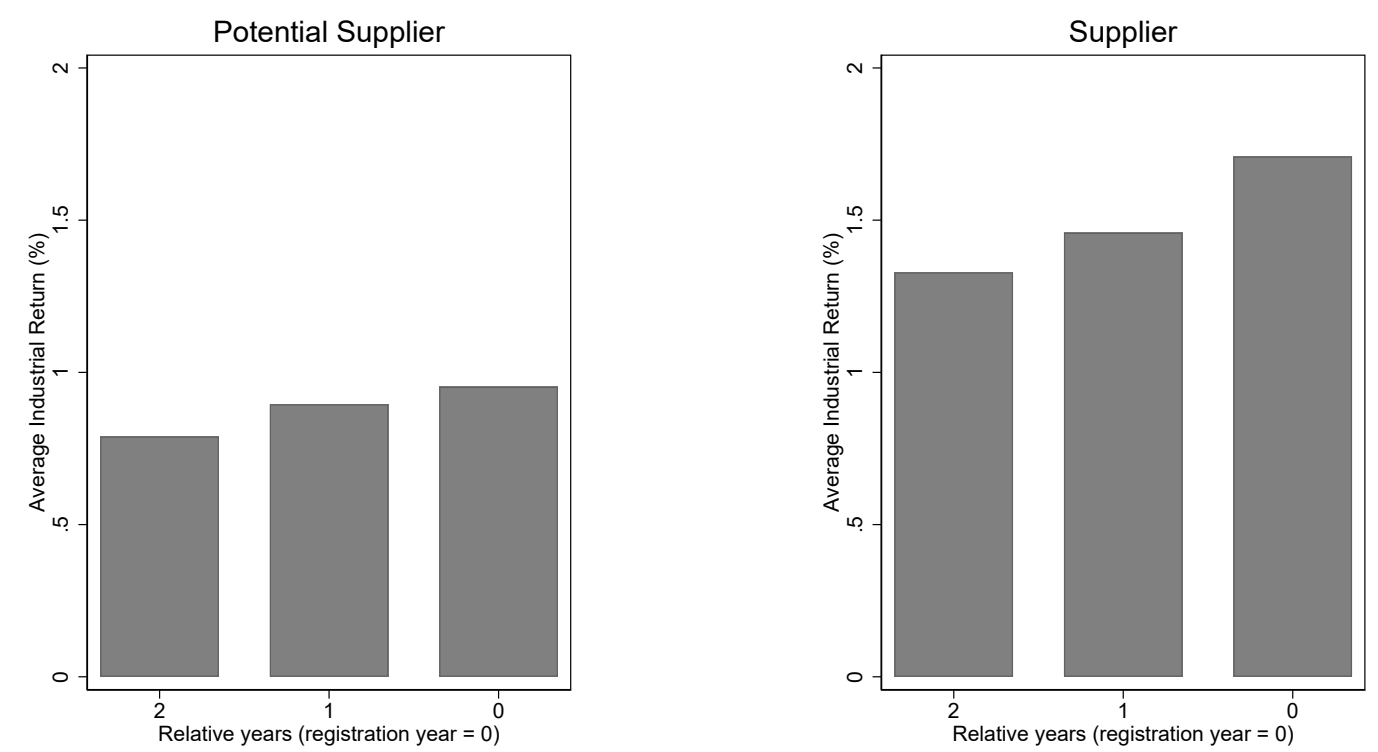

(a) Average industrial returns over relative years
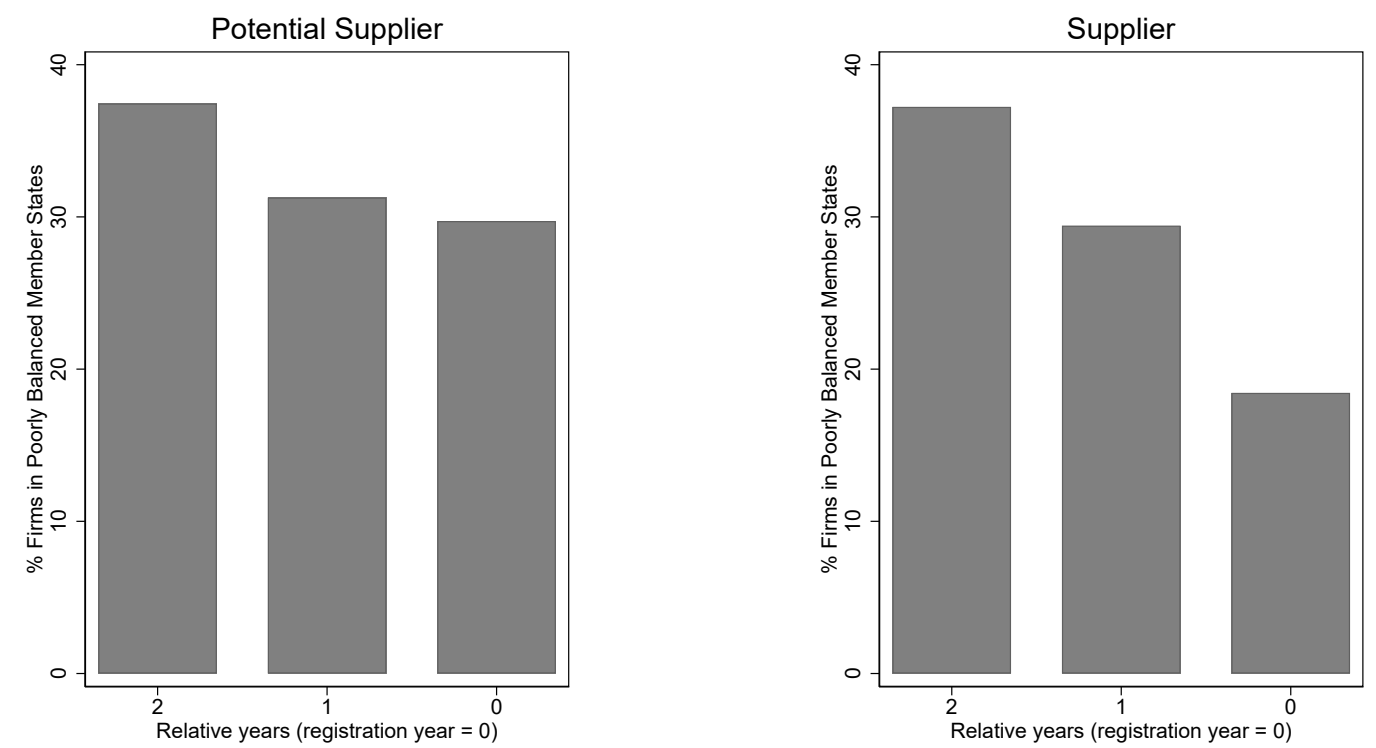

(b) Percentage of firms in poorly balanced MS over relative years

Notes: relative years indicate the value of the variable $\ell$ years before the year the firm registered with CERN. 
Table 6: Logit model $\mathcal{M}_{2}$ with lags of "Ind. Ret." and "Poorly Balanced"

\begin{tabular}{|c|c|c|c|}
\hline & $\begin{array}{l}(1) \\
\mathcal{M}_{2}\end{array}$ & $\mathcal{M}_{2}^{(\ell=1)}$ & $\mathcal{M}_{2}^{(\ell=2)}$ \\
\hline & & $\ell$ & \\
\hline & 0 & 1 & 2 \\
\hline \multirow[t]{2}{*}{ Hi-tech } & $0.408^{*}$ & $0.410^{*}$ & $0.398^{*}$ \\
\hline & $(0.216)$ & $(0.216)$ & $(0.215)$ \\
\hline \multirow[t]{2}{*}{ Ind. Ret. $(\mathrm{t}=\ell)$} & $0.661^{* * *}$ & $0.651^{* * *}$ & $0.673^{* * *}$ \\
\hline & $(0.117)$ & $(0.116)$ & $(0.129)$ \\
\hline \multirow[t]{2}{*}{ Ind. Ret. $\times$ Poorly Bal. $(\mathrm{t}=\ell)$} & 0.157 & 0.118 & 0.197 \\
\hline & $(0.678)$ & $(0.686)$ & $(0.721)$ \\
\hline \multirow[t]{2}{*}{ Years in CERN DB } & $0.394^{* * *}$ & $0.489^{* * *}$ & $0.494^{* * *}$ \\
\hline & $(0.150)$ & $(0.147)$ & $(0.147)$ \\
\hline \multirow[t]{2}{*}{$\log$ (no. orders) } & $0.569^{* * *}$ & $0.564^{* * *}$ & $0.552^{* * *}$ \\
\hline & $(0.131)$ & $(0.133)$ & $(0.131)$ \\
\hline Size FE & $\checkmark$ & $\checkmark$ & $\checkmark$ \\
\hline Sector FE & $\checkmark$ & $\checkmark$ & $\checkmark$ \\
\hline Registration year FE & $\checkmark$ & $\checkmark$ & $\checkmark$ \\
\hline $\mathrm{N}$ & 541 & 541 & 541 \\
\hline
\end{tabular}

Notes: see notes to Table 2. Lags of variables are associated with $\ell>0: t=\ell$ denotes the value of the variable $\ell$ years before registering with CERN for the first time.

\subsection{Supply and service contracts}

As discussed in Section 3.3, CERN distinguishes between contracts for supplies and services. Service contracts are multi-year contracts for the provision of services to be performed on the CERN site. Supply contracts cover any contract that is not defined as a service contract and include $\mathrm{R} \& \mathrm{D}$ contracts, maintenance and leasing contracts covering data processing, printing and telecommunication equipment. Our data does not allow to distinguish between supplies and services, therefore our main results are based on the average industrial return for these two kind of contracts. Similarly, we have defined MS as poorly balanced if their industrial returns for both supplies and contracts are lower than a certain threshold value. 


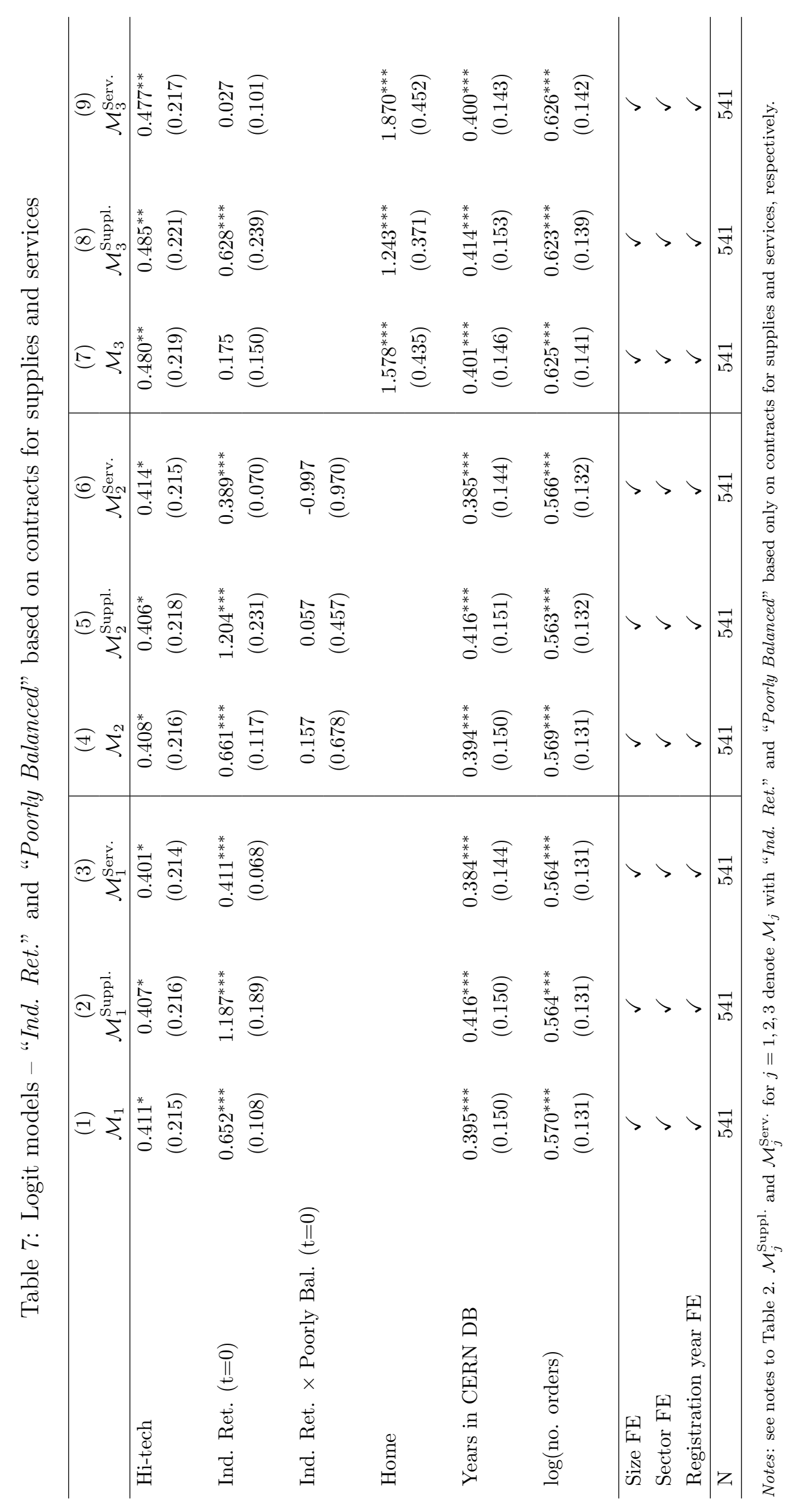


In Table 7 we re-estimate all our models considering the MS's status and industrial return based either on supplies or services. Our main results are mostly unaffected, however we notice that in all cases when focusing on supply contracts the coefficient on "Ind. Ret." tends to increase.

\section{Discussion and conclusions}

We have explored the factors that are expected to affect firms' probability of becoming a supplier of a BSC such as CERN. Our results suggest that, along with a set of elements related to firms' ability to navigate the tendering process, there is an evident tension between suppliers' technological expertise and political constraints related with CERN's procurement rules. While it is clear that firms bringing hi-tech knowledge have a higher chance of becoming suppliers, the weight of belonging to MS that, relative to what they receive via contracts, contribute significantly to CERN's budget or that are awarded a preferential treatment since they are poorly balanced, is relevant. Possible underlying motivations and justifications for the introduction of the juste retour principle include its contribution towards the creation and growth of pan-European scientific capability in space research (Physics World, 1988) and its role as a force that can counterbalance the benefits accruing to the country hosting the infrastructure or BSC (Hallonsten, 2012). Our empirical results pointing to the relevance of an idea of fair return in CERN's procurement activity and documenting the existence of a strong home premium effect in CERN's procurement activity could be interpreted as an argument in favor of the latter motivation. The juste retour policy could thus be a force contrasting the potential negative implications of a home premium in the award of contracts of BSC and, as such, be considered as a useful tool. However, the juste retour principle is suggested to be going against EU competition policies OECD (2010) and, as such, has not been inspiring the procurement rules of some of the more recent collaborations in European BSC. For example, the ESS and ITER do not include juste retour in their procurement procedures. In its place, a new orientation, itself not without potential problems relies on translating MS's financial contribution to the collaboration's common budget into in-kind contributions of materials and buildings. It should however be noted that CERN's policy 
explicitly states that the main principle guiding procurement is that technical and financial requirements are met, making the just retour principle second tier. In order to provide an evaluation of the juste retour principle and try and determine whether its net effect is positive, without distorting fair competition among European countries, another aspect should be considered. As mentioned throughout the paper, BSC generate a number of externalities, including those related to procurement. There are, for example, positive externalities accruing to firms involved in the BSC's activities especially in terms of innovative output. These effects should be considered when examining the juste retour principle, framing it alongside the more general attitude toward and design of innovation policies. Furthermore, the effects of public procurement activities of CERN and other BSCs with similar policies and rules could spill over beyond the geographic boundaries of the firms awarded contracts. These effects, while difficult to account for and estimate (and not explicitly examined in the present paper), could partially offset or at blur the impact of a juste retour policy. If spillovers are positive, this could dampen the negative implications of the fair return principle, while if negative the opposite, reinforcing effect could be present. Understanding whether the just retour principle can be justified on the basis of economic efficiency entails, from an aggregate perspective, a general equilibrium analysis of the pros and cons of the adoption of this principle. This principle might distort the optimal allocation of contracts by imposing a geographic distribution based on contributions to the BSC's budget, but could also have positive effects. These might include, as mentioned above, a correction of biases in favor of countries hosting the BSC in the allocation of procurement contracts and positive effects on innovative activities, both direct and indirect, in the form of spillovers. Taken together, these considerations concerning the relationship between the juste retour principle and the home premium, on the one hand, and innovation policies, on the other, suggest that ascertaining whether this principle is justified or not is a complex problem. They also suggest that the alleged incompatibility with EU competition laws is not clear-cut, as several other forces are at play. While an answer to the question of whether the juste retour principle is to be allowed and encouraged is beyond the scope of the present paper, our findings on the existence of a home premium in CERN's procurement activities and the importance of geographic industrial returns suggest the complexity of the balance between contributions to 
the common budget and contracts received and hint towards the importance of considering a fair return for MS participating in a BSC. The innovation externalities and the interplay between the just retour principle and innovation public policies is an avenue for future research, but might be a basis for a justification of this principle, which is still inspiring the procurement activities of several European BSCs.

Our results also allow to draw some policy considerations. First, the impact of public procurement at BSC are potentially high in terms of knowledge spillovers for suppliers and the economy as a whole (see e.g. Autio et al., 2004), profits of suppliers (Florio et al., 2018b) and their innovative activity (Åberg and Bengtson, 2015).

This also has implications in terms of public policies for innovation, through technological innovations and spillovers resulting from procurement activities of BSCs. Hansen and Wouters (2012), for example, focus on the space sector and examine the impact of the European Space Agency's activities, especially in terms of returns for industrial policy. Eerme (2016) provides an overview of previous findings evaluating the economic impact of space contacts by ESA. By considering a metric computed as the ratio of total indirect industrial effects from space-related contracts ${ }^{10}$ to the total value of the same contracts, country level estimates of multiplier of investing in space-related programs are provided. Values from country-specific studies suggest that this multiplier effect ranges from 1.4 in Belgium to 4.75 in Norway ${ }^{11}$ These figures, while difficult to compare given the differences in the underlying studies ${ }^{12}$, suggest the importance of understanding the organization and rules of procurement processes in science-related investments.

The choice of suppliers and their geographical location also has a role in public policies. In fact, our results should be framed within the wider debate on the role of BSCs as potential instruments for national innovation policies. If CERN's procurement activity is seen as an element contributing to a country's public effort towards innovation, the factors influencing the probability of becoming a supplier should be understood and accepted. We have shown how both technological and political factors affect this process and this should be taken

\footnotetext{
${ }^{10}$ Measured for example as increased sales or turnover of suppliers after being awarded the contract)

11 With data from, respectively, 2010 and 2013.

${ }^{12}$ Mainly related to differences in the definition of the numerator of the multiplier
} 
into account when analyzing the role of BSCs as instruments of overall innovation policies. Our empirical results suggest that the probability of becoming a supplier is driven first and foremost by technological factors, while the importance of procedures and procurement rules is not negligible, but smaller in relative terms. We have also documented the existence of a relevant home premium in the choice of the suppliers, an aspect which can be considered part of CERN's procurement rules and constraints. While more research is needed to pinpoint the origins and implications of this premium, factors that might influence this effect are related to the localized nature of some goods and services to be provided and to the potential role of procurement as a form of compensation for localized negative spillovers from BSC.

Moreover, since CERN might commit to the construction of Future Circular Collider (FCC), a much bigger collider with respect to LHC (i.e. planned diameter of 80-100 km) to explore the implications of more intense collisions, an understanding of its procurement policy, highlighting potential aspects that could be improved upon, appears relevant (FCC Collaboration, 2019; Bastianin and Florio, 2019). While we have documented that CERN does not apply a strict juste retour policy when awarding contracts to firms located in different MS, it is clear that a MS's position in terms of balanced industrial returns is a significant element in the decision process. An evaluation of the implications of this policy, which has in time been criticized (Hameri and Nordberg, 1999), in terms of the characteristic of the firms selected to become CERN suppliers might be necessary before significant amounts ${ }^{13}$ of public funds are committed to the construction of a new, giant, research infrastructure such as FCC.

Lastly, the constraints related with the achievement of a juste retour affect - directly or indirectly - the procurement policy of many European BSCs and international bodies whose budget is financed by the public funds of their Member States. Therefore, our results have policy implications that go beyond BSCs.

\footnotetext{
${ }^{13}$ Preliminary figures are in the range of 15 billion euros, see https://home.cern/news and https:// fcc-cdr.web.cern.ch/
} 


\section{Acknowledgments}

This paper has been prepared while the first author was a contributor to the FCC study (DCC-GOV-CC-0004, EDMS 1390795) in the frame of the Collaboration Agreement between the University of Milan and CERN (KE3044/ATS). We thank Massimo Florio for insightful discussion and seminar participants at the University of Milan, at the University of Milan - Bicocca and participants at XXXI Annual Conference of the Italian Society of Public Economics (SIEP) and at 60th Annual Conference of the Italian Economic Association (SIE). We also thank two anonymous referees for constructive and helpful comments. The usual disclaimer applies.

\section{References}

Åberg, S. and Bengtson, A. (2015). Does CERN procurement result in innovation? Innovation: The European Journal of Social Science Research, 28(3):360-383.

Autio, E., Hameri, A.-P., and Vuola, O. (2004). A framework of industrial knowledge spillovers in big-science centers. Research Policy, 33(1):107-126.

Bastianin, A. and Florio, M. (2019). Initial guidelines for a social cost-benefit analysis of the FCC programme. Technical Report CERN-ACC-2019-0037, CERN, Geneva.

Battistoni, G., Genco, M., Marsilio, M., Pancotti, C., Rossi, S., and Vignetti, S. (2016). Cost-benefit analysis of applied research infrastructure. evidence from health care. Technological Forecasting and Social Change, 112:79-91.

Bianchi-Streit, M., Blackburne, N., Budde, R., Reitz, H., Sagnell, B., Schmied, H., and Schorr, B. (1984). Economic utility resulting from CERN contracts (second study). CERN, 84-14. Available online at (last accessed Mar. 2019): https://cds.cern.ch.

Bressan, B. and Bianchi-Streit, M. (2005). CERN technology transfers to industry and society. CERN, Geneva, available online at (last accessed Oct. 2017): https://cds.cern.ch. 
Breton, A. and Salmon, P. (1996). Are discriminatory procurement policies motivated by protectionism? Kyklos, 49(1):47-68.

Brülhart, M. and Trionfetti, F. (2009). A test of trade theories when expenditure is home biased. European Economic Review, 53(7):830 - 845.

Caloffi, A. and Gambarotto, F. (2017). Cognitive distance in public procurement and public-private partnerships: An analysis of the construction sector. Environment and Planning C: Politics and Space, 35(5):765-783.

Carboni, C., Iossa, E., and Mattera, G. (2018). Barriers towards foreign firms in international public procurement markets: a review. Economia e Politica Industriale, 45(1):85-107.

Castelnovo, P., Florio, M., Forte, S., Rossi, L., and Sirtori, E. (2018). The economic impact of technological procurement for large-scale research infrastructures: Evidence from the Large Hadron Collider at CERN. Research Policy, 47(9):1853-1867.

CERN (1993a). CERN annual report 1993. Available online at (last accessed Oct. 2017): http://cds.cern.ch/record/1516861.

CERN (1993b). Report of the finance committee working group on cern purchasing policy and procedures. 98th Session of Council, 247th Meeting of Finance Committee, (CERN/2006 - CERN/FC/3662). Available online at (last accessed: March 2017): http://cds. cern. ch/record/33166.

CERN (2015). CERN financial rules. Available online at (last accessed Oct. 2017): https: //espace.cern.ch/fp-procedures/procurement.

CERN (2017). The Medium-Term Plan for the period 2018-2022 and draft budget of the Organization for the sixty-fourth financial year 2018. Available online at (last accessed: May 2019): http://cds.cern.ch/record/2270947.

CERN (2018). CERN quick facts 2018. Available online at (last accessed: March 2019): https://home. cern/resources/brochure/cern/quick-facts. 
CERN (2019a). The economic benefits of the LHC research programme. Is it worth investing in large-scale research facilities? Available online at (last accessed March 2019): http: //fcc-cdr.web.cern.ch/webkit/.

CERN (2019b). LHC the guide. Available online at (last accessed March 2019): http: //press.cern/press-kit.

Christensen, T., Lægreid, P., and Rovik, K. A. (2020). Organization theory and the public sector: Instrument, culture and myth. Routledge.

Cudraz, E. (2019). EMBL procurement.

Edler, J. and Georghiou, L. (2007). Public procurement and innovation-resurrecting the demand side. Research Policy, 36(7):949-963.

Eerme, T. (2016). Indirect industrial effects from space investments. Space Policy, 38:12-21.

ESFRI - European Strategy Forum on Research Infrastructures (2018). Strategy report on research infrastructures - Roadmap 2018. Available online at (last accessed: March 2019): http://roadmap2018.esfri.eu/.

Evans, L. (2016). Particle accelerators at CERN: From the early days to the LHC and beyond. Technological Forecasting and Social Change, 112(C):4-12.

FCC Collaboration (2019). FCC physics opportunities - Future Circular Collider Conceptual Design Report - Volume 1. European Physical Journal C, 79(6):1-161.

Florio, M., Bastianin, A., and Castelnovo, P. (2018a). The socio-economic impact of a breakthrough in the particle accelerators' technology: A research agenda. Nuclear Instruments and Methods in Physics Research Section A: Accelerators, Spectrometers, Detectors and Associated Equipment, 909:21 - 26.

Florio, M., Giffoni, F., Giunta, A., and Sirtori, E. (2018b). Big science, learning, and innovation: evidence from CERN procurement. Industrial and Corporate Change, 27(5):915-936. 
Flynn, A. and Davis, P. (2017). Investigating the effect of tendering capabilities on sme activity and performance in public contract competitions. International Small Business Journal, 35(4):449-469.

Flynn, A., McKevitt, D., and Davis, P. (2015). The impact of size on small and medium-sized enterprise public sector tendering. International Small Business Journal, 33(4):443-461.

Hallonsten, O. (2012). Continuity and change in the politics of european scientific collaboration. Journal of Contemporary European Research, 8(3).

Hameri, A.-P. and Nordberg, M. (1999). Tendering and contracting of new, emerging technologies. Technovation, 19:457-465.

Hansen, R. and Wouters, J. (2012). Towards an eu industrial policy for the space sectorlessons from Galileo. Space Policy, 28(2):94-101.

Helmers, C. and Overman, H. G. (2017). My precious! The location and diffusion of scientific research: evidence from the Synchrotron Diamond Light Source. The Economic Journal, 127(604):2006-2040.

Jewell, C. (2008). CERN and innovation - the heart of the matter. WIPO Magazine, 6:10-14.

Le Cacheux, J. (2005). Budget européen: le poison du juste retour. Etudes et Recherches 41, Notre Europe.

Nilsen, V. and Anelli, G. (2016). Knowledge transfer at CERN. Technological Forecasting and Social Change, 112:113-120.

OECD (2010). Establishing large international research infrastructures: Issues and options. Available online at (last accessed: May 2019): http://www.oecd.org/science.

OECD (2016). Survey on public procurement. OECD, Paris. Available online at (last accessed: May 2019): https://qdd.oecd.org.

Patrucco, A. S., Walker, H., Luzzini, D., and Ronchi, S. (2019). Which shape fits best? designing the organizational form of local government procurement. Journal of Purchasing and Supply Management, 25(3). 
Physics World (1988). Juste retour unjustified? Physics World, 1(11):3-4.

Rickard, S. J. and Kono, D. Y. (2014). Think globally, buy locally: International agreements and government procurement. The Review of International Organizations, 9(3):333-352.

Rodgers, P. (1992). Industry: Bonjour, juste retour? Physics World, 5(8):8-9.

Shingal, A. (2015). Econometric analyses of home bias in government procurement. Review of International Economics, 23(1):188-219.

Tammi, T., Saastamoinen, J., and Reijonen, H. (2014). Market orientation and SMEs' activity in public sector procurement participation. Journal of Public Procurement, 14(3):304327.

Tuertscher, P., Garud, R., and Kumaraswamy, A. (2014). Justification and Interlaced Knowledge at ATLAS, CERN. Organization Science, 25(6):1579-1608.

Unnervik, A. (2018). Doing business with CERN. Available online at (last accessed: July 2020) https://indi.to/PTKKs.

Vuola, O. and Hameri, A.-P. (2006). Mutually benefiting joint innovation process between industry and big-science. Technovation, 26(1):3-12.

White, H. (1980). A heteroskedasticity-consistent covariance matrix estimator and a direct test for heteroskedasticity. Econometrica, 48(4):817-838.

Williams, A. M. (2014). Local preferencing for local suppliers: Examining the use of locality in public procurement. Public Money \& Management, 34(3):165-172.

Zilverschoon, C. J. (1974). Some aspects of the realization of high-energy projects in cern. In Jesse A. and Colin, J.S. (eds.) Meeting on Technology arising from High-energy Physics, vol. 1. (CERN-74-09-V-1). Available online at (last accessed: March 2017): http://cds . cern.ch/record/186200. 
Public procurement in Big Science: politics or technology? The case of CERN

Not-for-publication Appendix 


\section{A Additional results}

Table A1: Different specifications of $\mathcal{M}_{2}$

\begin{tabular}{|c|c|c|c|}
\hline & (1) & $(2)$ & $(3)$ \\
\hline Ind. Ret. $\times$ Poorly Bal. $(t=0)$ & $\mathcal{M}_{2}$ & $\mathcal{M}_{2}^{\prime}$ & $\mathcal{M}_{2}^{\prime \prime}$ \\
\hline \multirow[t]{2}{*}{ Hi-tech } & $0.408^{*}$ & $0.402^{*}$ & $0.412^{*}$ \\
\hline & $(0.216)$ & $(0.216)$ & $(0.215)$ \\
\hline \multirow[t]{2}{*}{ Ind. Ret. $(\mathrm{t}=0)$} & $0.661^{* * *}$ & $0.639^{* * *}$ & $0.646^{* * *}$ \\
\hline & $(0.117)$ & $(0.118)$ & $(0.119)$ \\
\hline \multirow[t]{2}{*}{ Poorly Bal. $(t=0)$} & & -0.769 & -0.032 \\
\hline & & $(0.791)$ & $(0.280)$ \\
\hline \multirow[t]{2}{*}{ Ind Ret. $\times$ Poorly Bal. $(t=0)$} & 0.157 & 1.934 & \\
\hline & $(0.678)$ & $(1.891)$ & \\
\hline \multirow[t]{2}{*}{ Years in CERN DB } & $0.394^{* * *}$ & $0.384^{* *}$ & $0.395^{* * *}$ \\
\hline & $(0.150)$ & $(0.154)$ & $(0.150)$ \\
\hline \multirow[t]{2}{*}{$\log ($ no. orders $)$} & $0.569^{* * *}$ & $0.572^{* * *}$ & $0.570^{* * *}$ \\
\hline & & & $(0.131)$ \\
\hline Size FE & $\checkmark$ & $\checkmark$ & $\checkmark$ \\
\hline Sector FE & $\checkmark$ & $\checkmark$ & $\checkmark$ \\
\hline Registration year FE & $\checkmark$ & $\checkmark$ & $\checkmark$ \\
\hline $\mathrm{N}$ & 541 & 541 & 541 \\
\hline
\end{tabular}

Notes: heteroscedasticity-consistent standard errors in parentheses; “*” $p$-value $<0.10$, " "**" $p$-value $<0.05$, "***" $p$-value $<$ 0.01 ; "N" is the number of observations. We included sets of dichotomous variables corresponding to size of firms ("Size FE"), two-digits NACE codes are included ("Sector FE") and year of registration with CERN ("Registration year FE"). 